\title{
Construir puentes entre la investigación y las políticas educativas: ¿Cómo pueden ayudar los Observatorios ciudadanos?
}

Building Bridges between Research and Educational Policy: How Can Citizen Observatories Help?

\author{
Arcelia Martínez Bordón \\ Universidad Iberoamericana Ciudad de México, México \\ arcelia.martinez@ibero.mx \\ Georgina Hermida Montoya \\ Universidad Nacional Autónoma de México, México \\ georgina.hermida@comunidad.unam.mx
}

\section{RESUMEN}

El objetivo del presente artículo es analizar el rol potencial de los observatorios ciudadanos en México para tender puentes entre la investigación educativa y las políticas públicas. A partir de un estudio cualitativo de tipo documental y empírico, se discute el posible rol de estos actores como intermediarios estratégicos, gracias a la riqueza de sus características: tanto de las generales relacionadas con su figura asociativa, como de las específicas con los ámbitos educativos monitoreados por cada caso, las acciones realizadas, la información producida y sus públicos objetivo. Al retomar la preocupación de Pablo Latapí, de "procurar una mayor presencia de la investigación educativa en la hechura de políticas" $y$ de la necesidad de fortalecer las agencias ciudadanas, el texto pretende abonar a tres campos del conocimiento: i) los vínculos entre la investigación y las políticas públicas; ii) la participación social en la "vigilancia" de la educación, y iii) la gobernanza del sistema educativo, esto último, especialmente en un escenario como el mexicano donde el derecho a la educación es difícilmente exigible y justiciable.

Palabras clave: observatorios ciudadanos, participación social, rendición de cuentas, política educativa, investigación educativa

\section{ABSTRACT}

The objective of this article is to analyze the potential role of citizen observatories in Mexico to build bridges between educational research and public policies. From a qualitative study of documentary and empirical type, the possible role of these actors as strategic intermediaries is discussed, thanks to the richness of their characteristics. Whether from the general ones, corresponding to their associative figure, as well as from the specific ones, related to the educational fields monitored by each case, the actions carried out, the information produced, and their target audiences. By retaking the concern of Pablo Latapí, of "seeking a greater presence of educational research in the making of policies" and of the need to strengthen citizen agencies, the text aims to contribute to three fields of knowledge: i) links between research and public policies, ii) social participation in the "surveillance" of education, and iii) the governance of the education system; the latter, especially in a scenario like Mexico where the right to education is hardly enforceable and justiciable.

Keywords: citizen observatories, social participation, accountability, educational policy, educational research 


\section{INTRODUCCIÓN}

En su discurso de clausura del IX Congreso Nacional de Investigación Educativa realizado en Mérida, Yucatán, en 2007, Pablo Latapí apuntó seis consejos-recomendaciones para no perder la esperanza en que la investigación abonara a la mejora del sistema educativo: i) abrir espacios para jóvenes en los centros de investigación, frente a una comunidad de especialistas que envejece; ii) descentralizar la investigación educativa; iii) priorizar proyectos radicales que rompan con lo establecido y lo ya probado como inefectivo, prestando especial interés a las áreas poco atendidas en la investigación educativa; iv) ser consecuentes con las convicciones éticas en favor de la justicia, estableciendo como prioridad nacional a las poblaciones históricamente marginadas; v) dialogar con los agentes de decisión y procurar una mayor presencia de la investigación educativa en la hechura de políticas, y, vi) buscar canales de difusión diferentes de los académicos para contribuir a la opinión pública y al fortalecimiento de movimientos sociales.

Quien conozca de cerca el trabajo y la vida de Don Pablo Latapí sabrá que estas recomendaciones no fueron sólo para los demás, sino que él las asumió plenamente en su afán por vincular la investigación educativa con el diseño y operación de mejores políticas. Así, por ejemplo, Roberto Rodríguez (2018) menciona que Don Pablo fungió como el líder del hoy extinto Observatorio Ciudadano de la Educación (OCE), el cual fue fundado en 1998 y fue pionero en su ámbito; además, Latapí jugó un rol muy importante en la inclusión del tema de la participación social en la Ley General de Educación de 1993.

Las aportaciones de Pablo Latapí al campo de la investigación educativa fueron, de hecho, sustanciales. Hoy, más de doce años después de aquel famoso discurso de clausura, en este artículo se busca hacer especial eco a las sugerencias de Don Pablo, particularmente la de abrir la investigación educativa hacia las políticas públicas, apostar por proyectos radicales, utilizar medios de difusión no convencionales y que los investigadores seamos congruentes con las convicciones éticas en favor de la justicia. Es a partir de ellas, y en el marco de la X edición de la Cátedra Pablo Latapí Sarre-organizada anualmente por el Sistema Universitario Jesuita- como surge este 
texto, que tiene como objetivo analizar el rol potencial de los observatorios ciudadanos en México para tender puentes entre la investigación y las políticas educativas, de acuerdo con la noción teórica de los observatorios y lo que reportan casos concretos respecto a sí mismos. En el artículo se presentan avances de una investigación en curso, que tiene su antecedente en la ponencia presentada por las autoras y otro investigador, Alejandro Reyes Juárez, en el XV Congreso Nacional de Investigación Educativa organizado bienalmente por el Consejo Mexicano de Investigación Educativa (Comie) y que, en esta ocasión, tuvo lugar en Acapulco, Guerrero, a finales de noviembre de 2019.

Con la finalidad de lograr el objetivo propuesto, se hizo un estudio de corte cualitativo que combinó la investigación documental con la empírica. En un primer momento, se revisó la literatura producida en torno a los observatorios ciudadanos y a la relación que guardan la investigación y las políticas públicas en general y, de manera particular, con las políticas educativas. Posteriormente, se incorporó un componente empírico al trabajo, cuya unidad de análisis fueron los actores colectivos en México que, desde la ciudadanía, han observado las decisiones, acciones u omisiones de los gobernantes en el ámbito educativo. Así, se hizo un mapeo de tales actores y se realizó un análisis a profundidad de los contenidos publicados en sus medios de comunicación oficiales (páginas web, redes sociales, etc.) y de algunas de sus producciones escritas y audiovisuales. Lo anterior permitió construir una primera caracterización de los ámbitos de observación de estas instancias, que todavía es una materia poco explorada en la investigación educativa, pese al potencial de los observatorios para incrementar la incidencia de la investigación en las políticas educativas.

El artículo se estructura en cuatro apartados. El primero busca recuperar parte del debate sobre la escasa relación que existe entre la investigación y las políticas públicas -entre ellas, las educativascomo terreno de juego en el cual pueden entrar los observatorios ciudadanos. En un segundo apartado se realiza una descripción de estas figuras asociativas a partir de nociones teóricas y de la revisión de casos concretos que, como veremos, las convierte en intermediarias potenciales entre la investigación y las políticas públicas. Poste- 
riormente, en el tercer apartado, se presenta un mapeo de observatorios que fueron fundados ex professo para cumplir con funciones que la literatura ha identificado como propias de un observatorio ciudadano -aun cuando ellos mismos no se autodenominen de esa manera-, que buscan incidir en temas de interés público y participar en el debate educativo nacional de, al menos, una temática educativa. En este apartado se hace una revisión sobre lo que dichos observatorios reportan como sus fines, sobre lo que hacen u observan, el tipo de información que producen, cuáles son sus públicos objetivos, entre otros elementos que permiten hacer una primera caracterización de los observatorios de políticas educativas en México. Antes de ofrecer algunas reflexiones finales, se propone una forma de pensar la intermediación potencial de estos grupos ciudadanos entre las políticas educativas y la evaluación e investigación educativas, a partir de los lazos que sostienen con cada uno de estos dos elementos para impulsar un tercer vínculo entre ellos, que sirva de puente para reducir la histórica distancia a la que se encuentran.

Como podrá apreciarse a lo largo del texto, es visible la postura vigilante de los observatorios de políticas educativas en México para identificar los vacíos y prácticas antidemocráticas en la toma de decisiones y acciones de los gobiernos, y de promoción, directa o indirecta, de una cultura de rendición de cuentas, de exigencia ciudadana y de gobernanza del sistema educativo. Ello cumple con el fin último de las recomendaciones que hacía Latapí (2008, p. 295) a los investigadores educativos: "para que esta sociedad [civil] se convierta en actor real, en sujeto reclamante de sus derechos, en contralor vigilante de las acciones gubernamentales".

\section{DE LA AÚN ESCASA VINCULACIÓN ENTRE LA INVESTIGACIÓN Y LAS POLÍTICAS PÚBLICAS}

Jaime Moreles (2009) sostiene que, pese a que se ha promovido normativamente el uso de la investigación en la toma de decisiones, dicha relación se ha estudiado muy poco. En el último estado del conocimiento publicado por el Comie en 2013, los usos de la investigación son considerados un "asunto emergente"; incluso se menciona que fue la primera vez que se incorporó esta temática en 
el estado del arte preparado cada década por dicho órgano colegiado. ¿Cuáles son algunas de las posibles explicaciones que se pueden encontrar en la literatura especializada respecto a la desvinculación entre la investigación y las políticas públicas?

A estas alturas, es inobjetable que, a los hacedores de políticas, en general, les ha faltado voluntad para incorporar los resultados de la investigación a sus decisiones, a veces por completo y, otras veces, como señala Weiss (2016), aunque lo han hecho, han sido guiados por un interés más utilitario que por uno genuino en la realización de un trabajo competente. Al hacer referencia a un instrumento técnico de política educativa resultante de evaluaciones e investigaciones coordinadas por el extinto Instituto Nacional para la Evaluación de la Educación (INEE), Carlos Rodríguez (en Martínez Bordón, 2018, p. 280) dice: "las directrices del INEE son de tipo indicativo, por lo que no hay ninguna garantía ni incentivo para que las autoridades las cumplan". El investigador citado hace referencia a la tendencia de las autoridades a no considerar lo que otras instancias gubernamentales y sociales les señalan -aun cuando sus demandas están basadas en evidencia-, mientras no exista un marco legal que lo haga de acatamiento obligatorio para los tomadores de decisiones. Ello deja a merced de voluntades individuales -guiadas, principalmente, por lógicas políticas- incorporar el conocimiento especializado en la toma de decisiones que incremente las posibilidades de construir mejores sociedades.

Sin embargo, también los investigadores se han mantenido relativamente alejados del proceso de las políticas públicas -incluidas las educativas-. Latapí (1977) señalaba que, entre los especialistas, existen dos propósitos al investigar, los cuales, difícilmente, coinciden. Por un lado, se encuentra el deseo de incrementar los conocimientos académicos sobre la materia y, por el otro, el de incidir en la toma de decisiones de política educativa. En el último estado del conocimiento del Comie, Lya Sañudo (2013) reporta como principal hallazgo que el conocimiento científico en torno a la educación es producido, en buena medida, como fin en sí mismo y se traduce, principalmente, en los productos de difusión tradicionales de la academia (artículos científicos y libros).

De acuerdo con Sañudo (2013), Jalisco es la única entidad federativa para la que fue posible recuperar datos más precisos al respec- 
to. En este estado se encontró que 55.3\% de la investigación educativa estatal se hizo con el fin prioritario de producir conocimiento en sí mismo, mientras el porcentaje restante buscó traducirse en una variedad muy amplia de elementos. Cabe mencionar que las políticas públicas fueron agregadas en un grupo de productos que involucran actividades de diseño, desde tales intervenciones, hasta guías didácticas y talleres, todo lo que suma $17 \%$ de las respuestas. En cuanto a potenciales usuarios del conocimiento, de los 267 investigadores que respondieron la encuesta reportada, únicamente $9.8 \%$ señaló a un cúmulo poco preciso de posibles beneficiarios, entre los que podrían encontrarse los tomadores de decisiones públicas (pues al conjunto se le denominó "procesos de gestión institucional, seguimiento de egresados, organismos gubernamentales y mejora de la educación normal"), y 1.5\% reportó expresamente las "políticas" como beneficiario potencial.

Así, Sañudo (2013) concluyó que el impacto de la investigación educativa necesita transitar de un esquema unilateral en el cual se produce conocimiento y se deja su uso a responsabilidad de sus posibles receptores, a un modelo que sea dialógico, desde el diseño de la investigación, hasta la discusión, reflexión y posible incorporación de los resultados al campo concreto de los procesos educativos. En la misma línea, Bracho (2016) menciona que, más allá de idear una necesaria, mas no suficiente- estrategia de difundir los resultados de la evaluación -o la investigación-, se requiere que desde el diseño del procedimiento para generar el conocimiento se tengan presentes tanto sus posibles usos, como sus potenciales usuarios.

Carlos Rodríguez (en Martínez Bordón, 2018) es afín a la postura de lejanía por parte de los investigadores. Señala que existen tres posiciones predominantes entre ellos: i) quienes estudian temas más cercanos al plano de la abstracción, ii) quienes buscan participar en debates públicos, y iii) quienes buscan incidir sólo en aquellos temas en los que han desarrollado un expertisse avalado por su trabajo y el reconocimiento de sus pares académicos. Aunado a ello, Diego Juárez y Rosa Guadalupe Mendoza (en Martínez Bordón, 2018), coinciden en que la mayoría de los investigadores buscan incidir a un nivel micro que, si bien es beneficioso, ha dejado de lado la preocupación por el nivel macro de la educación. 
Martínez Bordón (2018) sostiene que la evaluación y la investigación se mantienen alejadas de las políticas públicas, en buena medida, porque entre los especialistas existe una fuerte dificultad para comunicarse de manera más fluida con los tomadores de decisiones, lo que se relaciona con la ampliamente diseminada creencia de que hacerlo significa renunciar a una postura crítica. La autora también habla del obstáculo que representa el hecho de que los investigadores educativos constituyan un grupo con insuficiente trabajo en redes y alianzas que impulsen la inclusión de sus preocupaciones en la agenda de discusión; lo que se necesita, señala, es "que nuestro trabajo también encuentre eco entre otros expertos e investigadores ...para, a partir de ahí [de discutir y generar acuerdos], colocar propuestas y soluciones en el debate" (Martínez Bordón, 2018, p. 287). En el mismo sentido, Rosa Guadalupe Mendoza (en Martínez Bordón, 2018) señala que los investigadores deben traducir sus hallazgos a los lenguajes de otros actores, profundizar en la lógica de la toma de decisiones para entenderla, dialogar con los políticos, e identificar lo que es relevante investigar para la sociedad y en el proceso de las políticas públicas. En palabras de Weiss (1979, p. 431):

Tal vez sea momento de que los científicos sociales presten atención a las necesidades de la hechura de políticas y consideren sensatamente qué pueden hacer, no necesariamente para incrementar el uso de la investigación, sino para mejorar la contribución que la investigación puede aportar a la racionalidad de la política social. ${ }^{1}$

Algunas interpretaciones de la distancia o cercanía entre la investigación y las políticas educativas han considerado las voluntades, tanto de tomadores de decisiones, como de investigadores, y han agregado otros actores, procesos y escalas a la ecuación. Carlos Muñoz Izquierdo (en Loyo y Solórzano, 2013), por ejemplo, señalaba que la incidencia de la investigación en las políticas educativas depende de la confluencia de, por lo menos, tres procesos: en primer lugar, uno epistemológico que representa la validación de los procesos y hallazgos de la investigación por parte de la comunidad

\footnotetext{
${ }^{1}$ Traducción propia del inglés original.
} 
especializada; en segundo lugar, un proceso político que supone la compatibilidad de valores y creencias entre políticos e investigadores $\mathrm{y}$, en tercer lugar, un proceso administrativo que incluye dinámicas de diversos tipos para que una intervención pública pueda ser implementada.

A su vez, Moreles (2009) hace referencia a cuatro factores que explican -aunque no garantizan- el uso de la investigación en diversos espacios -incluida la toma de decisiones de política-: i) características de la investigación y los investigadores, siendo los nexos informales e indirectos, las negociaciones políticas y la elección de ciertos temas polémicos los elementos que tienden a tener más peso para incidir; ii) las formas de difusión, que refieren tanto a la manera en la que se presenta el conocimiento, como a los medios para difundirlo; iii) las particularidades de los usuarios potenciales del conocimiento, donde son especialmente relevantes su receptividad, experiencia y conocimiento previo de los temas, y iv) el contexto en el que se busca que la investigación tenga incidencia, especialmente el momento político vivido, la existencia de canales para el uso de la investigación y la disponibilidad de recursos.

En concordancia con esta visión sobre la complejidad de los vínculos entre las políticas públicas y la investigación, Flores Crespo (2013, p. 285) señala que "el uso e impacto de la investigación y el conocimiento especializado está profundamente mediado por una serie de relaciones humanas y personales y, por lo tanto, no basta apelar a la calidad de la evidencia para esperar su utilización”. En el mismo sentido, aunque desde otro enfoque, Navarro, Zúńiga y Arenas (2018) mencionan que los retos para el diseño y la implementación de políticas basadas en evidencia pueden verse en dos escalas: micro y macro. Entre los principales retos que identifican a nivel micro se encuentra la existencia -o la falta- de relaciones personales entre los tomadores de decisiones y los investigadores, así como la situación profesional de estos últimos y el empate -o no- de los intereses de ambos actores. En cuanto a los retos a nivel macro, las autoras identifican la priorización que se hace de ciertas fuentes para informar la toma de decisiones, la ausencia de evaluaciones robustas para demostrar el logro de mejores resultados a partir de la evidencia y el relego del proceso de las políticas públicas en los estu- 
dios de las políticas basadas en evidencia, pues éstos se han centrado, primordialmente, en incrementar el impacto unidireccional de las investigaciones.

A ello se suman los seis modelos en los que la investigación puede ser usada en la toma de decisiones de política pública propuestos por Carol Weiss (1979), aparentemente vigentes a la fecha. El primero, denominado "Modelo impulsado por el conocimiento", supone la generación de conocimiento como fin principal y, en caso de que sus hipótesis sean probadas exitosamente en la práctica, entonces se deja el uso de los resultados como algo probable. El segundo se llama "Modelo de solución de problemas" y en él se realiza un estudio ex professo para dar solución a un problema particular identificado; por lo tanto, los hallazgos son utilizados más directamente. El tercero es el "Modelo interactivo" en el que el conocimiento científico representa una, entre muchas fuentes de información, de las que se valen los políticos para tomar las decisiones, especialmente porque los tiempos de la hechura de políticas y de la investigación son disímiles.

El cuarto es el "Modelo político" en el que la investigación se convierte, en palabras de la misma Weiss (1979, p. 429), en “munición para el bando que encuentre sus conclusiones favorables y de apoyo", ${ }^{2}$ en tanto es utilizada para respaldar decisiones ya tomadas, neutralizar oponentes, convencer a indecisos y reforzar el apoyo de simpatizantes. En el quinto, llamado "Modelo táctico", los tomadores de decisiones mencionan la realización de investigaciones -sin brindar detalles-, tanto para hacer pasar sus decisiones por unas basadas en evidencia, como para dilatar las acciones excusándose en que están esperando los resultados de aquéllas. El sexto modelo y, posiblemente, en el que la investigación tiene más incidencia en la arena política, es el "Modelo ilustrativo"; en éste, los hallazgos específicos de la investigación no inciden directamente en la toma de decisiones, sino que los conceptos y perspectivas que se derivan de ella van permeando sectores informados de la sociedad civil, así como el proceso de la hechura de políticas, a veces, incluso no de forma consciente.

\footnotetext{
${ }^{2}$ Traducción propia del inglés original. Las cursivas son de las autoras para enfatizar la alusión a la guerra en este modelo de relación entre la investigación y las políticas públicas.
} 
Varios ańos después de realizar este aporte, Weiss (2016) agrega que existen tres principales tipos de productos de la investigación sobre políticas públicas que buscan llegar a la arena de decisión: los datos, las ideas y los argumentos. Sin embargo, señala que los datos técnicos difícilmente alcanzan esta esfera, siendo las ideas (generalizaciones basadas en datos, a veces, poco precisas) y los argumentos (dilución selectiva de datos que construye un producto persuasivo de defensa activa de una posición), los productos más buscados y utilizados por los tomadores de decisiones. Pese a que estos dos productos suelen diluir los hallazgos de la investigación, anota Weiss (2016), su construcción e incorporación en las políticas públicas resulta positiva en diversas dimensiones, desde la reconceptualización y jerarquización de los problemas públicos por parte de la sociedad civil, hasta las decisiones finalmente tomadas por los agentes de decisión. A estos beneficios del uso indirecto de la investigación y la evaluación, Tiana (1997) agrega el hecho de exponer públicamente la ineficacia y el impacto real de determinadas acciones o enfoques de política pública, independientemente de su arraigo y de los mensajes difundidos por la propaganda política. Todos los beneficios aquí enunciados hacen del uso no instrumental de la investigación uno -paradójicamente- de más largo alcance.

Por su parte, Latapí (2005) considera que, tal vez, la explicación más convincente a esta distancia entre la investigación y las políticas públicas toma en consideración los regímenes políticos. Sostiene que:

Hay mayores probabilidades de que el conocimiento especializado sea tomado en cuenta en las políticas públicas cuando existe un régimen democrático [énfasis agregado] en el que las decisiones gubernamentales proceden de procesos participativos en los que la sociedad -y en ella los investigadores- expresan sus posiciones (Latapí, 2005, p. 28).

De acuerdo con Martínez Bordón (2018, p. 271), lo cierto es que existe una "difícil, nunca lineal, relación entre investigación y toma de decisiones", por lo que, como lo externaron los diversos panelistas reunidos en la X Cátedra Pablo Latapí Sarre (UIA, 2019a, 2019b, 2019c, 2019d), la incidencia en la hechura de las políticas 
públicas sigue siendo el gran pendiente de la investigación educativa, en especial si se toma en consideración la anotación que hacen Detrich, Keyworth y States (2016) cuando resaltan la importancia de los procesos de implementación de las políticas basadas en evidencia para que pueda hablarse de una relación verdaderamente efectiva entre la investigación -o la evaluación- y la toma de decisiones; es decir, de un vínculo que realmente se traduzca en beneficios para las niñas, niños y jóvenes que dan razón de ser a los sistemas educativos.

Así pues, habrá que reflexionar en torno a la normatividad, los espacios y los mecanismos institucionales actualmente existentes en México, así como sobre los recursos de la ciudadanía y de los tomadores de decisiones, entre muchos otros aspectos mencionados en este apartado, para que la gobernanza, entendida como la define Aguilar (2006, p. 70), sea una realidad en el campo de la educación: "el proceso de gobierno o de dirección de la sociedad mediante el cual una sociedad se dirige, gobierna y gestiona a sí misma”.

\section{EL POTENCIAL DE LOS OBSERVATORIOS CIUDADANOS DE SERVIR COMO INTERMEDIARIOS ENTRE LA INVESTIGACIÓN Y LAS POLÍTICAS EDUCATIVAS}

Si bien las decisiones de política educativa son finalmente tomadas por los gobernantes en turno, existe una responsabilidad compartida entre los diversos actores que componen el sistema educativo para que éste cumpla con sus fines últimos. Latapí (2005, p. 8) decía que "la participación [social es] evidentemente necesaria para mejorar el carácter democrático de la toma de decisiones de política educativa y en última instancia la calidad del servicio educativo". Aquí, por tanto, pueden y deben entrar en escena los observatorios de políticas educativas. En este apartado se reflexiona sobre las características de los observatorios ciudadanos que permiten esperar de éstos un rol vinculante entre la investigación y las políticas educativas.

\section{¿Qué son los observatorios?}

Natal y Díaz (2014) definen a los observatorios ciudadanos como figuras asociativas que reúnen en un espacio autónomo a individuos $\mathrm{u}$ 
organizaciones pertenecientes a la sociedad civil para dar seguimiento a uno o varios temas de interés público, "buscando comprenderlos, incidir o construir opinión pública alrededor de éstos" (Natal y Díaz, 2014, p. 27). De acuerdo con los autores, los observatorios tienen cinco actividades centrales que no son mutuamente excluyentes, ni simultáneamente necesarias: recopilación de la información; decodificación o análisis de la información; comunicación de los resultados; búsqueda de incidencia, y construcción de opinión pública.

De acuerdo con Martínez, Valencia y Díaz (2014, p. 66), los observatorios ciudadanos se encargan de procesar datos, "informar, vigilar, controlar, evaluar, denunciar, transparentar, democratizar, educar, generar opinión pública e incidir en las acciones y políticas públicas”. La Organización de Estados Americanos (OEA, 2015) resalta que la información alternativa producida por los observatorios ciudadanos, a partir de su vigilancia a la marcha institucional, posee diversos usuarios, desde los servidores públicos, para incrementar las posibilidades de que su gestión conduzca a los resultados esperados, hasta los ciudadanos que interactúan con la administración pública, sean o no la población objetivo de sus políticas públicas.

Por su parte, Flores Crespo (en Latapí, 2005) identifica tres grupos de actores de la participación social en educación que no se excluyen entre sí: los expertos, los agentes de decisión política y los practicantes. Debido al foco de este artículo, se mencionará de forma breve únicamente el desglose que hace el autor del primer conjunto. Según Latapí (2005), Flores Crespo localiza en la categoría de "expertos" a los investigadores académicos en un sentido estricto, a los integrantes de consultorías y think tanks, a los intermediarios o brokers (que son intermediarios que difunden ampliamente el conocimiento), a los administradores de instituciones y a los investigadores que laboran en instituciones gubernamentales. Según esta clasificación, los observatorios ciudadanos de la educación podrían moverse en los tres primeros subgrupos de expertos enlistados, pues no pocos observatorios están conformados por investigadores académicos, algunos pueden ser think tanks, y prácticamente en su totalidad buscan ser intermediarios, ya sea entre diversos sectores de la sociedad -usualmente entre la civil y la política-, o entre procesos que consideran valiosos, como la investigación educativa y la hechura de las políticas públicas. 
En este momento resulta fundamental resaltar la diferencia nodal existente entre los observatorios ciudadanos y los grupos de interés o de cabildeo que, tal como lo señalan Natal y Díaz (2014), reside en la forma que cada uno tiene de incidir sobre las políticas públicas. Mientras los grupos de cabildeo (o lobbys) se basan en la negociación política para incidir, los observatorios ciudadanos construyen y promueven ideales "técnicos" o estándares sociales a ser alcanzados. En sus propias palabras:

Los Observatorios trabajan a partir de indicadores que se establecen como metas y objetivos, que responden a perspectivas técnicas o teóricas sobre formas en las que la sociedad tendría un mejor nivel o forma de vida. Al hacer esto, los Observatorios contrastan la realidad con opciones de futuros posibles y deseables. ... Un Observatorio observa, por tanto, "lo que es" desde la perspectiva o el anhelo, a veces implícito, de un "deber ser" (Natal y Díaz, 2014, p. 47).

Se considera, pues, que mientras los grupos de cabildeo suelen negociar involucrando intereses que emergen desde lo privado, los observatorios ciudadanos buscan incidir sosteniendo una visión construida más desde y para lo público. Quienes escriben este texto estiman que es vital hacer hincapié en esta distinción entre ambos grupos, pues ello puede incrementar la legitimidad de los observatorios ciudadanos en el sistema educativo y, en esa medida, su potencial vinculante y capacidad de incidencia en la toma de decisiones.

\section{¿Qué características comparten los observatorios ciudadanos?}

A continuación, se identifican algunas de las principales características de la figura de los observatorios ciudadanos que permiten pensar en su potencial para vincular la investigación con la toma de decisiones.

\section{i) Origen sustentado en la necesidad de involucrar a más} actores sociales en la resolución de problemas públicos

Respecto a los factores mínimos, externos e internos, que tienden a caracterizar la aparición de los observatorios ciudadanos, Natal y 
Díaz (2014) identifican tres tendencias en el contexto mundial en los que surgen y operan estos grupos ciudadanos que, señalan, son condiciones mínimas para que los observatorios ciudadanos puedan tener algún nivel de incidencia.

El primer factor es un nuevo entendimiento del gobierno en el que su legitimidad ya no reside en su gobernabilidad (capacidad de gobernar, fuertemente sostenida, entre otras cosas, en las jerarquías administrativas), sino en la participación activa y amplia de la población relacionada, de alguna manera, con las acciones gubernamentales; también reside ahora en la coordinación Estatal entre y con los diversos sectores sociales. Estas dos condiciones, consideran, son los dos pilares de la gobernanza que se erige como una forma de gobierno más horizontal y, al serlo, como una más eficaz para guiar el desarrollo.

El segundo factor de surgimiento es la consolidación de la sociedad civil en términos técnicos (mayor experticia) y políticos (mayores habilidades para ejercer la propia voz). Ambas cuestiones han permitido que las instancias en las que se ha organizado la sociedad civil, como los observatorios, sean reconocidas como actores en la arena pública. El tercer factor es, en realidad, una triada de elementos que caracterizan un entorno favorable para la fundación y operación de los observatorios, a saber: un nivel aceptable de desarrollo de la democracia para la ciudadanía, en especial en cuanto a estabilidad e institucionalidad; niveles relativamente altos de escolaridad o conocimientos técnicos, de capacidad de articulación y de cultura sobre "lo público" entre la sociedad civil, además de un mínimo de recursos financieros, y un entorno relativamente tecnificado que facilite el acceso, procesamiento y difusión de datos.

\section{ii) Sus agendas incorporan una dimensión ética más allá del interés privado}

A estos elementos se suma que los observatorios, en cuanto sociedad
civil organizada, establecen sus agendas, propósitos y acciones a par-
tir de una dimensión ética que busca superar los intereses privados
e, incluso, los colocados en las agendas gubernamentales. Brito (en
Latapí, 2005, p. 16) define a la sociedad civil como "el conjunto 
de ciudadanos organizados como tales para actuar en el campo de lo público, en busca del bien común, sin ánimo de lucro personal, sin buscar el poder político ni la adhesión institucional a un partido". En ese sentido, puede decirse que los observatorios ciudadanos tienen como eje de acción la "reciprocidad", móvil al que Latapí (2005) hace referencia al hablar del trabajo realizado de manera voluntaria en la consolidación de la vida democrática, sin encontrarse coaccionados por la ley para hacerlo -como sí se halla el gobierno-. Esto puede complementarse con la creciente aspiración social, mencionada por Olvera (2003), a una democracia menos vertical, elitista y monopolizada, y más incluyente, vigilada y responsable.

\section{iii) Tienen un interés explícito en la evidencia}

Otra característica común entre los observatorios ciudadanos es el interés explícito por la evidencia emanada de la investigación y la evaluación. Aunque las formas en las que estas figuras se relacionan con la evidencia se abordan a mayor profundidad en el siguiente apartado, aquí resulta relevante señalar que los observatorios de políticas educativas funcionan como canales alternativos de difusión del conocimiento - producido o no por ellos- de los temas en los que ponen su foco, para que sea materia prima en el diálogo público en y entre diversos sectores de la sociedad civil y, en ese sentido, también son potenciadores de agencias ciudadanas.

Así, una de las principales formas en las que los observatorios potencian a la ciudadanía es, como señalan Natal y Díaz (2014), reduciendo las asimetrías de información entre ella y los políticos, pues operan, entre otras cuestiones, como sistemas de información. Estos autores consideran a los observatorios ciudadanos como cajas en las que entra información proveniente de documentos públicos y privados, registros gráficos, testimonios, notas periodísticas, entre otras -aquí se incluirían los productos de la evaluación y la investigación-, para ser procesados a partir de lo que llaman políticas y protocolos para el procesamiento de la información, haciendo uso de sistemas de información eficientes, todo lo que, posteriormente, deviene en reportes, diagnósticos, análisis, entre otros, ya de autoría de los observatorios. 
Al respecto, Peruzzotti (en Natal y Díaz, 2014) resalta que los observatorios generan fuentes de información de carácter autónomo que pueden llenar vacíos de la información brindada por el Estado y desafiar los datos oficiales. Estas condiciones más igualitarias para la rendición de cuentas, sostienen Natal y Díaz (2014, p. 40), permiten "la construcción de un diálogo inter-sistémico, entre ciudadanos y tomadores de decisiones, cuyo objetivo es la discusión de lo público sobre la base de información 'técnica', ideales u objetivos mutuamente aceptados". En el mismo sentido, la perspectiva de Latapí consistía en que, en palabras de Schmelkes (2018, 12' y 20'):

Una sociedad bien informada tendría mucho mayor capacidad de influir certeramente en la toma de decisiones. ...La relación entre la investigación y la distribución del conocimiento para crear una sociedad bien informada es un ejercicio de profunda democracia que es lo que permite [a la investigación] influir en la toma de decisiones ... [Latapí] plantea la necesidad de avanzar en democracia y en participación social en materia de educación, [pues] sostiene que mientras la sociedad no crezca en su capacidad de exigir cuentas al gobierno, a los legisladores, a los sindicatos, la mala calidad y la desigual distribución de nuestra educación no podrán revertirse.

A su vez, la relación entre los observatorios ciudadanos de políticas educativas y la investigación también se da en cuanto no son pocas las agrupaciones que tienen a investigadores académicos entre sus filas. Latapí (2005) hizo hincapié en la característica del OCE de que sus miembros fueran especialistas en los temas, y señaló que ello permitía que la discusión pública sobre los ámbitos educativos y las propuestas de políticas gubernamentales elaboradas por el observatorio se vieran reforzadas por sus conocimientos especializados en el campo. Toda proporción guardada, ello podría extenderse a aquellos observatorios cuyos integrantes, pese a no ser investigadores en el sentido estricto de la palabra, hacen uso -de una u otra forma- de conocimiento especializado sobre los temas para realizar sus diversas acciones de incidencia, de tal forma que, como señalan Natal y Díaz (2014, p. 47), "los Observatorios son quizá los espacios más técnicos de la participación ciudadana”. 
En general, al relacionarse con la evidencia emanada de la investigación y la evaluación los observatorios ciudadanos pueden incrementar el potencial de incidencia, en especial al incrementar su legitimidad percibida y, por tanto, la base social que les permite incidir indirectamente por medio de la presión social. Además, cuando los observatorios consideran la dimensión política de la investigación y logran, como señala Majone (1997), tejer el conocimiento como argumentos, pueden ver sus inquietudes y propuestas más fácilmente incorporadas en las decisiones de los gobernantes, ya que se ha identificado en diversas investigaciones (Martínez Bordón, 2018; Weiss, 2016) que los argumentos representan una de las formas adoptadas por los resultados de las evaluaciones y las investigaciones, y los que poseen mayores probabilidades de ser considerados evidencia en la toma de decisiones de política pública.

Es relevante advertir que existe un fuerte debate sobre por qué y cómo debe impulsarse el uso de la investigación en el proceso de las políticas públicas. Autores como Parsons (2007) han señalado que existe el riesgo de promover una sociedad guiada por el conocimiento como fórmula mágica para resolver problemas públicos y, por tanto, que éste llegue a convertirse en un fin en sí mismo; además -señala mientras retoma a diversos autores-, una visión tan racional del proceso de las políticas públicas, si bien puede incluir al conocimiento científico, excluye otros factores que son relevantes para la vida democrática. Aunque la posibilidad de dicho riesgo se reconoce, es fundamental resaltar que en los escenarios aquí planteados los actores que estarían -y están- haciendo uso y promoción de la investigación educativa son miembros de la sociedad civil, organizados alrededor de ideales ulteriores de sociedades deseables, los cuales pueden o no incluir una dimensión de racionalidad, pero que, sin duda, no se limitan a ella. Así, los observatorios ciudadanos pueden ser, incluso, una forma de prevenir el uso de la investigación como fin en sí mismo, al buscar complementar el saber técnico con la movilización social.

\section{iv) Son actores que trabajan en colectivo}

Los observatorios ciudadanos tienen la posibilidad de superar las limitantes de la individualidad para incidir en la toma de decisiones 
de política pública, por ser un cuerpo colectivo. En algunos casos, la unión que potencia a los observatorios como figuras colectivas no sólo es entre individuos, sino entre organizaciones o movimientos de la sociedad civil. De acuerdo con Rodríguez (2018, 53’), Latapí consideraba que el trabajo colectivo de un observatorio era "un cambio de paradigma, digamos, el pasar de la asesoría individual, del modelo de consejero ilustrado a organizar un colectivo que pudiera hacer esa tarea; pero no solamente a través de sus conocimientos, sino de la presión de la opinión pública”.

Cabe hacer énfasis en que no bastan grandes masas de miembros pues, de acuerdo con Latapí (2005), los observatorios poseen mayores posibilidades de ejercer una participación social deseada si logran superar el hecho de ser una mera agrupación de individuos, para asumirse como un sujeto colectivo con preocupaciones, aportaciones y propuestas.

\section{v) Buscan generar opinión pública}

En quinto lugar, tenemos que los observatorios ciudadanos entran en la arena de la opinión pública de los temas que observan. Respecto a esto, no se trata de tener presencia en el debate como objetivo en sí mismo, sino en el sentido que Rodríguez (2018, 55’) comparte lo que veía Latapí, quien: "[tenía] una idea muy activista de qué es lo que podía hacer un grupo una vez que ya tenía visibilidad y presencia en los medios; ... su idea es que eso se capitalizara para promover un movimiento”. En ese sentido, Natal y Díaz (2014, p. 34) señalan que "los Observatorios que buscan construir opinión pública pueden ser también un locus importante para la ampliación de algunos derechos y la rendición de cuentas".

\section{vi) Su vigilancia es de carácter permanente}

Otra característica importante es el carácter permanente de la vigilancia ciudadana realizada por los observatorios. Natal y Díaz (2014) identifican dos tipos de formas asociativas: por un lado, se encuentran los movimientos sociales que emergen como consecuencia de acciones gubernamentales coyunturales y suelen estar 
compuestos de sectores sociales afectados por tales decisiones; por el otro, se encuentran las asociaciones ciudadanas permanentes y con altos niveles de profesionalización, que es donde se ubican los observatorios ciudadanos. Si bien las autoras de este artículo no niegan que las formas asociativas puedan derivarse de las coyunturales, sí reconocen que es hasta que se encuentran relativamente consolidadas y ejercen sus funciones de vigilancia de forma cotidiana, que pueden tener mayor incidencia en las políticas públicas y, entre otras cuestiones, la investigación educativa puede, tanto contribuir a esa consolidación, como ser parte de los puentes que su fortalecimiento le permita tender con las políticas.

Entonces, ¿mecanismos sociales para la rendición de cuentas?

Al llevar a cabo una observación vigilante de las materias públicas en las que los observatorios ciudadanos deciden fijar la mirada, éstos tienden a constituirse en mecanismos de rendición de cuentas, es decir, de hacer efectivamente responsables de sus actos a los gobernantes frente a sus gobernados y elevar el costo político de no tomar decisiones en determinados sentidos considerados deseables.

Al respecto, es importante nombrar las tres dimensiones de la rendición de cuentas que se han destacado en la literatura (Fox y Aceron, 2016; Natal y Díaz, 2014; Paul, Goetz y Jenkins citados en Ackerman, 2005), a saber: la vertical, la horizontal y la diagonal. En la vertical, también llamada "electoral", los ciudadanos utilizan su voto como herramienta central para juzgar -y castigar o recompensar- el desempeño de los gobernantes. Sin embargo, Natal y Díaz (2014, p. 35) señalan que a esta dimensión se le ha criticado que "el voto es una condición necesaria, más (sic) no suficiente para la [rendición de cuentas]", toda vez que las elecciones no son permanentes y sólo sirven para escudrinarar a las autoridades de forma ex post (una vez que las acciones u omisiones ya se han realizado).

Por otro lado, en la rendición de cuentas horizontal existen organismos dentro de la estructura gubernamental que, por su carácter legalmente autónomo, sirven de contrapeso a los gobernantes. De acuerdo con Natal y Díaz (2014), las principales fortalezas de esta dimensión son su carácter permanente -siempre que existan fun- 
cionarios o dependencias expresamente encargadas de supervisar a la burocracia-y, retomando a O’Donnell (en Natal y Díaz, 2014, p. 37), el que estos órganos Estatales "tienen autoridad legal y están fácticamente dispuestas y capacitadas (empowered) para emprender acciones que van desde el control rutinario hasta sanciones penales". Sin embargo, las principales limitantes que los autores encuentran en esta dimensión de la rendición de cuentas es el énfasis en la forma, sobre el fondo, de las decisiones gubernamentales, y en el hecho de que la responsabilidad directa de los políticos frente a los ciudadanos puede reducirse al considerar que únicamente dichas instancias pueden exigir la rendición de cuentas.

La rendición de cuentas diagonal o "social", por su parte, supone un mecanismo permanente de vigilancia y control ciudadanos sobre las autoridades desde espacios formales o informales. Pese a que una limitante aparente de esta dimensión puede ser su falta de mecanismos para sancionar legalmente a las autoridades, la rendición de cuentas horizontal -que sí tiende a poseer mecanismos de sanción, aunque de diferentes tipos y grados- y la diagonal -ejercida directamente por ciudadanos- no son excluyentes entre sí. Smulovitz y Peruzzotti (2003, pp. 327-328) señalan que:

El concepto de rendición de cuentas social amplía la concepción clásica del sistema de pesos y contrapesos entre las instituciones Estatales para incluir una arena social compuesta por una multitud de asociaciones autónomas y heterogéneas. En este sentido ...la esfera social [funge] como un poder de contrapeso que complementa los mecanismos horizontales de rendición de cuentas ... [cuyas iniciativas] pueden jugar un rol importante en atender muchos de los déficits de los mecanismos horizontales. ${ }^{3}$

De hecho, Natal y Díaz (2014) hacen hincapié en la posibilidad de que la dimensión social/diagonal, incluso, active mecanismos de rendición de cuentas horizontales. Además de coincidir con estos autores, las autoras consideramos que la dimensión diagonal de la rendición de cuentas también puede ayudar a alimentar la vertical,

\footnotetext{
${ }^{3}$ Traducción propia del inglés original.
} 
pues las tareas realizadas por la sociedad civil en materia de evaluación e investigación, tienen el potencial de nutrir la opinión pública, fortalecer movimientos sociales, entre otros procesos, que pueden influir en la evaluación que realizan los ciudadanos de sus autoridades para mantenerlos o colocarlos "en el poder". De esta forma, es apreciable que las dimensiones de rendición de cuentas no sólo se complementan en favor de responsabilizar ex ante (durante) y ex post (una vez consumados los actos) a los gobernantes frente a sus gobernados, sino que, particularmente, la dimensión diagonal puede jugar un rol de catalizador clave para poner en marcha las otras dimensiones de la rendición de cuentas, tan necesarias como ella misma. Como mencionan Peruzzotti y Smulovitz (2002, p. 211) al estudiar casos latinoamericanos: "los mecanismos sociales de rendición de cuentas pueden hacer una contribución crucial [énfasis agregado] al cumplimiento del Estado de derecho". ${ }^{4}$

En síntesis: los observatorios ciudadanos podrían ser catalogados dentro de este tercer tipo de mecanismos de rendición de cuentas, en tanto que, como lo señalara Latapí (2005), las democracias modernas no garantizan la gobernabilidad por su sola legitimidad electoral, sino que requieren de otros procedimientos de representación y participación de los grupos sociales.

Así, los observatorios son una forma de participación social que resulta fundamental para la consecución de políticas públicas democráticas. Si estas intervenciones Estatales están construidas desde procesos democráticos, sostenía Latapí (2005), tienen mayores probabilidades de mejorar los ámbitos de la vida social de interés. Dorantes, Morales y Torres (2019) sostienen que la sociedad civil organizada desempeña un rol trascendental en la vida democrática al prestar atención a los problemas de sociedades que se presentan como más plurales y complejas que antes. Natal y Díaz (2014) sostienen que la existencia de múltiples observatorios podría nutrir el pluralismo democrático al incrementar el nivel de discusión y deliberación entre actores.

En otras palabras, los organismos de la sociedad civil, entre los que se encuentran los observatorios ciudadanos, son la "'expresión

\footnotetext{
${ }^{4}$ Traducción propia del inglés original.
} 
multidimensional de una sociedad civil (SC) preocupada por sí misma, en busca de soluciones' a sus problemas" (Demos, citado en Latapí, 2005, p. 17), por lo que la operación de los observatorios de políticas educativas puede contribuir a virar la dirección desde una visión de gobernabilidad hacia un enfoque de gobernanza que, en palabras de Aguilar:

Es importante en nuestras sociedades, puesto que (re)establece la valía y capacidad de los actores sociales ...cuyos aportes contribuyen significativamente a la coordinación intrasocietal y cuyas capacidades subutilizadas son superiores en ciertos campos de interés público a las que posee el gobierno (Aguilar, 2006, p. 62).

A partir de esta breve caracterización de los observatorios ciudadanos y del primer acercamiento a las experiencias de observatorios de políticas educativas en México, sobre el cual se profundiza en el siguiente apartado, consideramos que estas figuras asociativas pueden convertirse en actores estratégicos para incidir en las políticas públicas y, de forma específica, tender puentes entre éstas y la investigación educativa.

\section{EXPERIENCIAS DE OBSERVATORIOS EDUCATIVOS EN MÉXICO: ¿QUIÉNES SON, QUÉ HAN OBSERVADO Y QUÉ ACTIVIDADES REALIZAN?}

En la presente investigación se retomaron agrupaciones sociales que, en algunos casos, no se nombran a sí mismas como observatorios ciudadanos, pese a que desempeñan funciones y poseen características de esta figura asociativa. Al respecto, Natal y Díaz (2014, p. 29) señalan que:

Hay muchos tipos de organizaciones que no se nombran Observatorios y que realizan actividades de monitoreo, análisis, construcción de opinión pública e incidencia. Por el contrario, hay otros que llevan el nombre de Observatorios Ciudadanos, y que no son resultado de un ejercicio desde la sociedad civil. 
Si bien la inclusión de tales agrupaciones debe discutirse a profundidad en futuras investigaciones, aquí se presenta como una propuesta de análisis, ya que se consideraron aquellos grupos asociativos de individuos u organizaciones que, autodenominándose o no como observatorios ciudadanos, cumplen con tres condiciones: i) haberse fundado ex professo para desempeñar una o más de las funciones de los observatorios ciudadanos señaladas por Natal y Díaz (2014), Martínez, Valencia y Díaz (2014) y la OEA (2015); ii) detentar la búsqueda de incidencia como parte de sus fines últimos; $y$, iii) tener -o haber tenido- presencia en el debate mexicano (nacional o estatal) sobre, cuando menos, una temática educativa. Con ello en mente y tras hacer una revisión a profundidad de los medios de comunicación oficiales (página web, redes sociales, etc.) de diversos observatorios y sus producciones (tanto escritas, como audiovisuales), Martínez Bordón, Reyes y Hermida (2019) identifican que en México han existido, al menos, doce observatorios ciudadanos encargados de vigilar las decisiones, acciones u omisiones de los tomadores de decisiones de política pública en una o más áreas de la educación en México.

Se localizaron dos tipos generales de observatorios de políticas educativas: por un lado, los focalizados, que tienen como única área de observación la educación, y, por el otro lado, los no focalizados, que monitorean un ámbito más general de la vida social, pero tienen a lo educativo como una de sus líneas centrales de seguimiento (véase gráfica 1). Entre los observatorios focalizados se encuentran (por orden cronológico de surgimiento): i) Observatorio Ciudadano de la Educación (OCE) -que es considerado la primera de las agrupaciones que fijaron la mirada en la política educativa a través de la vigilancia ciudadana-; ii) Hacia una Cultura Democrática, A.C. (ACUDE); iii) Suma por la Educación; iv) Mexicanos Primero; v) Consejo Ciudadano Autónomo por la Educación (CCAE); vi) Observatorio Veracruzano de la Educación (OVE), el cual se presentaba como el capítulo del OCE en Veracruz mientras éste existió y, posteriormente, vivió transformaciones importantes para, desde diciembre de 2018, convertirse en el Observatorio Veracruzano de la Agenda Educativa (OVAE); vii) Observatorio de Innovación Educativa del Tec de Monterrey (OIE-Tec); y, viii) Observatorio del Derecho a la Educación y la Justicia (ODEJ). 
En cuanto a los observatorios no focalizados en educación se incluyen (también por orden cronológico de aparición): i) Instituto Mexicano para la Competitividad (IMCO); ii) Centro de Estudios Espinosa Yglesias (CEEY); iii) México Evalúa; y, iv) Centro de Investigación Económica y Presupuestaria (CIEP).

Resulta interesante que el surgimiento de todos los observatorios de políticas educativas aquí retomados coincide temporalmente: todos datan de los albores del siglo XXI. Este momento empata con las tendencias mundiales de propagación de los observatorios ciudadanos señaladas por Natal y Díaz (2014) y mencionadas en el apartado anterior, pues en él convergen una mínima confianza ciudadana en la democracia, la disponibilidad de los recursos materiales y humanos necesarios, y la tecnificación del contexto. Otra anotación relevante es que, como menciona Rodríguez (2018) para el caso del OCE, la operación de estos observatorios ciudadanos no es estática, sino que pasa por diversas etapas, con más fortaleza e incidencia en unas, que en otras. Ello se explica por una conjunción de factores que pueden ser internos como, por ejemplo, la claridad y consenso -o su ausencia- de las funciones y medios del espacio en cuestión o la adscripción al mismo de ciertos miembros; y, también, puede deberse a factores externos a los observatorios, tales como momentos políticos adversos o favorables, y la disposición -o node los medios de comunicación para servir como plataformas de construcción democrática.

Una cuestión no menor respecto al rol potencial de los observatorios ciudadanos de tender puentes entre la investigación y las políticas educativas se desprende de los títulos de las publicaciones de los doce observatorios aludidos, de sus declaraciones de misión, visión, objetivos, prioridades y áreas de interés. En todos éstos es recurrente el uso de los siguientes conceptos: "mejores decisiones", "evidencia", "rendición de cuentas", "resultados", "transparencia”, "democratización", "exigencia ciudadana", "incidencia" y "corresponsabilidad". Además, todos sostienen explícitamente como principios la participación social, la ciudadanía activa y la transformación educativa. 
- Gráfica 1. Recuento histórico de los observatorios de políticas educativas en México

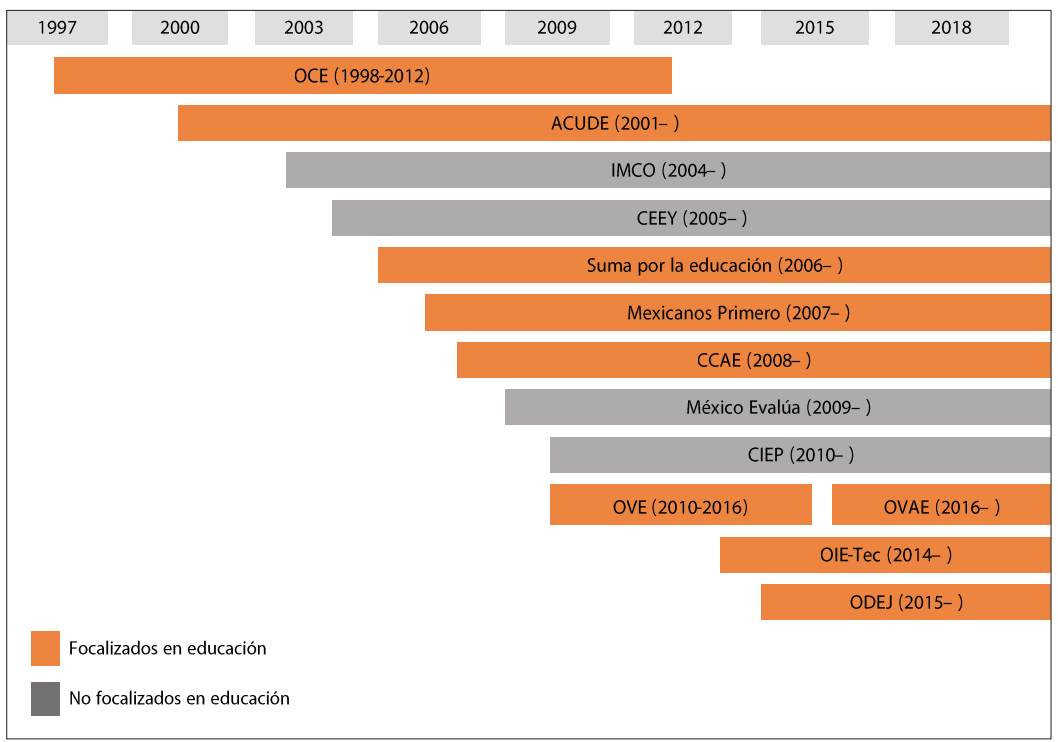

Nota. Se hicieron modificaciones mínimas en los periodos de operación de diversos observatorios en relación con lo inicialmente colocado en la ponencia de donde se retoman los datos base, ya que se encontraron nuevas fuentes de información que permitieron precisar y actualizar este mapeo. Respecto al OIE-Tec existe una inconsistencia en sus registros en torno al año de su fundación, indicándose en algunos de sus medios 2006 y en otros 2014; se toma el segundo, ya que su publicación principal comenzó a editarse en este año y es el que se señala en LinkedIn (red social profesional). En el caso del CCAE se presenta al observatorio como vigente; sin embargo, sus actividades públicas parecen haber cesado desde 2017, por lo que queda pendiente una confirmación por parte de sus miembros.

Fuente: adaptado de Martínez Bordón, Reyes y Hermida, 2019, p. 15.

Antes de profundizar en la caracterización de los observatorios de políticas educativas en México, cabe hacer la aclaración de que existe alta disparidad en el grado de disponibilidad y claridad de la información entre los observatorios. Esto se debe, en buena medida, a la escasez de recursos de algunos de ellos, a la falta de actualización de sus medios de comunicación oficiales o a la interrupción de sus operaciones momentánea o definitivamente. Particularmente complicado fue desentrańar la información del OVE-OVAE, del CCAE y del OCE. Aunque la página web y las redes sociales de los dos primeros poseen baja actividad, se encuentran parcialmente disponibles, por lo que fueron aquéllas y algunos de sus documentos (especialmente un documento de recomendaciones para las autoridades presentado formalmente a éstas en 2011 por el entonces OVE, y bole- 
tines realizados por el CCAE) las principales fuentes de información para sistematizar las experiencias.

Para el caso del OCE, que dejó de operar en 2012 y deshabilitó su página web (medio principal de comunicación), el análisis se basó en elementos recuperados de cuatro documentos: un artículo de 2005 escrito por Pablo Latapí en el que habla de la participación social en educación por medio del caso del OCE, el comunicado núm. 119 del OCE publicado en 2004 como recuento de su primer lustro de operación, el repaso de sus actividades durante 2009 por Hamui Sutton -su entonces presidenta- a diez años de su surgimiento, y la narración de la experiencia del observatorio realizada en 2018 por Roberto Rodríguez, uno de sus miembros. ${ }^{5}$

\section{¿Qué temas educativos han observado?}

$\mathrm{Al}$ realizar un acercamiento a lo colocado por los observatorios ciudadanos en sus medios de comunicación oficiales y en varias de sus publicaciones -en un sentido amplio, no necesariamente académico-, se identificaron 19 ámbitos de la educación a los que estas agrupaciones dan seguimiento. En la gráfica 2 se colocan los temas educativos abordados por ellos, a partir de la cantidad total de observatorios que los trabajan. Asimismo, para cada tema se indica si los observatorios son focalizados en educación o no, tomando como referencia que el total general de observatorios contemplados en este trabajo es de 12: ocho focalizados en el tema de educación y cuatro no focalizados.

Lo primero que se encuentra es que ninguno de los observatorios ciudadanos trabaja una sola área de lo educativo, pues fijan su mirada en, cuando menos, cuatro ámbitos, pese a que abordan sólo algunos con mayor profundidad. Esto es así incluso entre los observatorios no focalizados, sobre los que sorprende ver las múltiples vinculacio-

\footnotetext{
${ }^{5}$ Desde que fue elaborada la ponencia que se presentó en el XV CNIE-Comie ha habido ajustes en los datos sistematizados de varios observatorios, especialmente de estos tres casos, en la medida en que se ha encontrado y analizado nueva información de este tema relativamente inexplorado. Quedan pendientes, como parte de esta investigación, entrevistas a los miembros actuales o pasados de todos los observatorios y un rastreo exhaustivo de sus publicaciones para poder comprender los roles concretos y potenciales de estas figuras en el sistema educativo.
} 
nes que realizan entre la materia eje de su agrupación y la educación; lo que explica que, aunque los observatorios focalizados trabajan, naturalmente, más ámbitos de la educación, la diferencia numérica entre ellos y los no focalizados no sea tan marcada. Un ejemplo de ello es el CIEP, que tiene como foco de análisis del presupuesto público, pero lo relaciona con temas como el gasto educativo federalizado, las implicaciones fiscales de decisiones de gobierno como la obligatoriedad de la educación inicial y los programas de becas para capacitar a jóvenes, los retornos de la inversión educativa en forma de resultados de aprendizajes, calidad, empleabilidad y movilidad social, el sistema de pensiones y nómina docentes, entre otros aspectos.

Gráfica 2. Ámbitos de la educación abordados por los observatorios

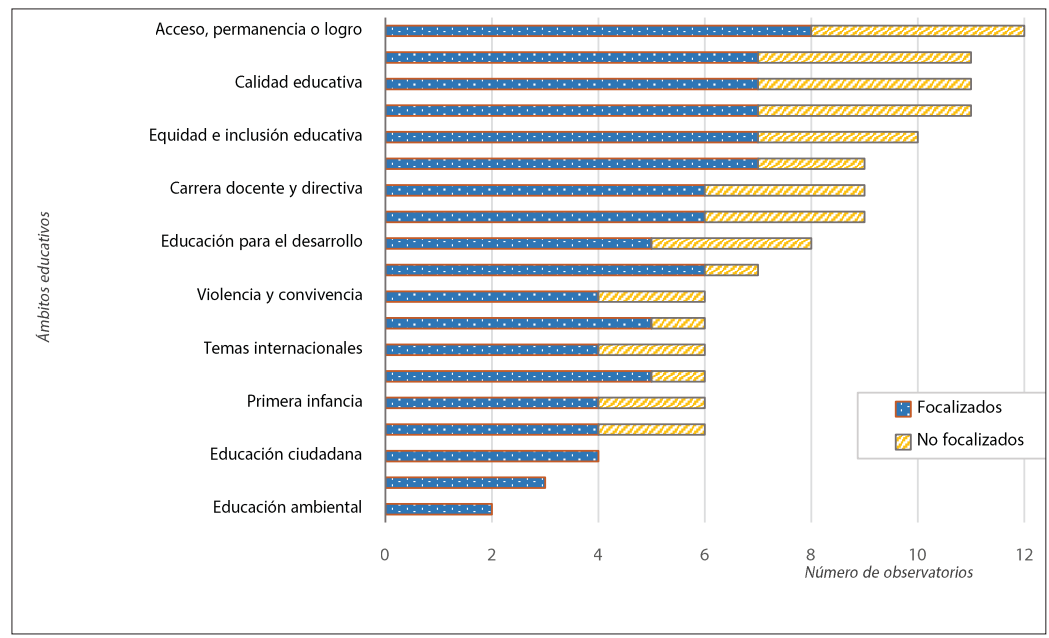

Nota. Sólo los temas educativos fueron sistematizados en el caso de los observatorios no focalizados. Por otro lado, las categorías temáticas no son utilizadas necesariamente con estos términos por los observatorios, sino que fueron construidas por las autoras y su colega para la ponencia a presentar en el XV CNIE-Comie; sin embargo, aquí se eliminaron dos de ellas para incorporarse en otras más generales y se incluyeron dos nuevas en relación con hallazgos recientes. Cabe mencionar que la frecuencia de observatorios registrados en cada ámbito no refiere a la asiduidad con la que los observatorios trabajan los temas, sino la cantidad de aquéllos que poseen, al menos, una publicación en sentido amplio, no netamente académico, en el ámbito educativo de referencia; además, estos datos fueron actualizados en relación con el mapeo previo, a partir de los avances de la investigación en curso.

Fuente: tomado de Martínez Bordón, Reyes y Hermida, 2019, p. 16. Adaptado, complementado y actualizado con datos recuperados de las páginas web oficiales, redes sociales y producciones diversas de los observatorios analizados. 
Se encontró también que entre los ámbitos educativos más vigilados por los observatorios ciudadanos están el acceso, la permanencia y el logro escolar, pues las 12 agrupaciones aludidas dan seguimiento a éstos. Le siguen las políticas y programas educativos, la calidad educativa y el financiamiento de la educación. No sorprende esto último, ya que el uso eficaz, eficiente y transparente de los recursos ha sido una tendencia clásica en la exigencia ciudadana por la rendición de cuentas, así como en la literatura especializada sobre el tema. Entre los temas menos observados están la educación ciudadana (abordada por cuatro de 12 observatorios), la educación integral (por tres de 12) y la ambiental (por dos de 12). Su escaso abordaje-hecho únicamente por parte de observatorios focalizados, por cierto-, tampoco sorprende, en cuanto se han reportado por el Comie $(1995,2003,2013)$ como áreas de la educación relativamente poco trabajadas, incluso por la academia.

Pese a no ser el área más ni menos trabajada por los observatorios ciudadanos estudiados, resulta muy interesante que la mitad de ellos han fijado su mirada, al menos en una ocasión, en la violencia y la convivencia en educación. La forma en la que lo han hecho, ha sido con acciones y productos que van desde artículos de opinión -como el OVE-OVAE, Mexicanos Primero, México Evalúa e IMCO-, hasta prácticas de intervención en los centros escolares, interpelando simultáneamente a las autoridades nacionales o locales -como ha sido el caso de ACUDE y Suma por la Educación-. En contraste, de acuerdo con lo señalado por Fierro (2019) en la X Cátedra Pablo Latapí Sarre, esta área temática no es lo suficientemente abordada por los investigadores educativos, menos lo es haciendo uso de enfoques fuera de lo tradicional.

Un reto importante de los observatorios es su descentralización, tanto en su ubicación geográfica, como en su enfoque para el análisis. En el caso de su ubicación, y a reserva de buscar más experiencias de observatorios en las entidades, se encontró que únicamente dos de los 12 observatorios identificados posee su centro de operaciones en una entidad federativa diferente a la Ciudad de México (el OIETec y el OVE-OVAE, en Nuevo León y Veracruz, respectivamente), aunque algunos de ellos, como Mexicanos Primero y el OCE, tienen -o tuvieron-capítulos estatales. El espacio geográfico en el que se 
ubiquen estas agrupaciones es relevante toda vez que suele estar relacionado -aunque no necesariamente- con la segunda dimensión del reto de descentralizarse, es decir, con la escala de las decisiones, acciones u omisiones de política educativa en la que fijan la mirada. En cuanto a este respecto, pese a que el panorama general muestra que la mitad de los observatorios contemplados han trabajado en algún momento el federalismo educativo, cabe mencionar que la vasta mayoría de ellos se enfocan principalmente en el ámbito federal de la educación. Al respecto, en su momento el observatorio focalizado en educación más emblemático en México, el OCE, admitía:

Hasta el momento, la panorámica nacional ha sido nuestro principal punto de vista; creemos necesario y conveniente recoger en próximos comunicados aquellos diagnósticos y reflexiones que, situados en planos estatales y locales, reflejen de mejor manera la diversidad del mapa educativo del país (OCE, 2004, p. 17).

Ello concuerda con las áreas y perspectivas históricamente poco trabajadas por la investigación educativa, pues el mismo Pablo Latapí hizo una invitación explícita a los investigadores para descentralizar sus estudios en el 2007 y, 12 ańos después, quienes participaron en la X edición de la Cátedra en honor a Latapí reforzaron que la centralización en la investigación educativa permanece como uno de sus principales retos. Este centralismo, como lo dijo principalmente Juárez (2019), va desde estudiar únicamente el duopolio sindical SNTE-CNTE al trabajar organizaciones magisteriales, hasta enfocarse sólo en las acciones del gobierno federal, dejando de lado los gobiernos locales que suelen ser el espacio gubernamental de contacto directo para las comunidades escolares.

\section{¿Qué actividades realizan los observatorios de políticas educativas?}

Se identificaron 17 acciones o funciones por medio de las cuales los observatorios ciudadanos en México vigilan los ámbitos educativos de su interés (véase gráfica 3). En la siguiente gráfica se ordenan de forma descendente las acciones que realizan los observatorios, a partir de 
la cantidad total de quienes lo hacen. A su vez, en cada función se presenta cuántos de los observatorios que la desempeñan son focalizados en educación y cuántos no lo son.

- Gráfica 3. Actividades realizadas por los observatorios de políticas educativas

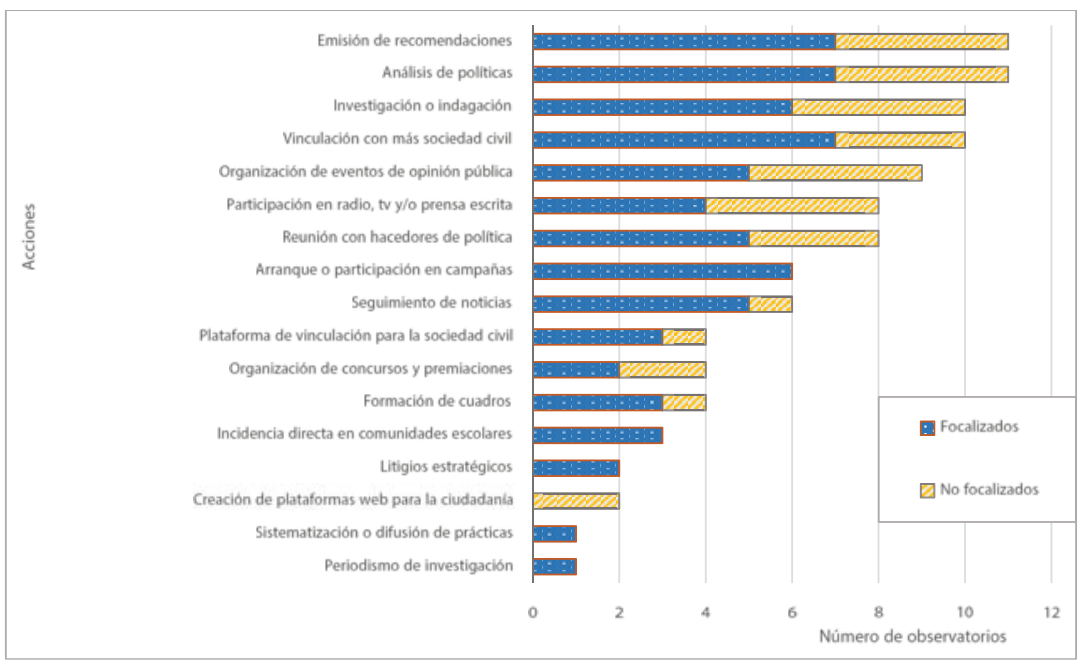

Nota. La frecuencia de observatorios registrados en cada acción corresponde netamente a cuántos de ellos hacen público que han realizado tales acciones, no a su asiduidad, ni al impacto obtenido con ellas.

Fuente: tomado de Martínez Bordón, Reyes y Hermida, 2019, p. 19. Los datos son complementados y actualizados con información de las páginas web oficiales, redes sociales y producciones diversas de los observatorios analizados. Elaboración propia.

Como puede apreciarse, las acciones menos realizadas por los observatorios son los litigios estratégicos, y creación de plataformas web para la exigencia ciudadana, pues sólo dos de los 12 las llevan a cabo; a lo que le sigue, con un sólo observatorio por acción, la sistematización o difusión de prácticas innovadoras (aunque otros declaran considerarlas importantes) y el periodismo de investigación, que busca ser un punto medio entre la narración de eventos educativos que ocurren en la coyuntura y la recuperación de evidencia para comunicarlos. La baja incidencia de los observatorios en estas acciones puede estar relacionada con que, en general, éstas requieren muy altos niveles de recursos financieros y de especialización, tanto tecnológica, como profesional. Es notable que ninguno de los observatorios focalizados en educación, por ejemplo, haya creado 
plataformas web que fortalezcan la capacidad de agencia ciudadana, mientras que la mitad de los observatorios no focalizados contemplados sí lo han hecho.

Por otra parte, entre las acciones más realizadas por los observatorios ciudadanos que fijan su mirada en la educación se encuentran, en orden de importancia: la emisión de recomendaciones y el análisis de políticas, ambas realizadas por 11 de 12 observatorios; la investigación o indagación y la vinculación con otros miembros de la sociedad civil, que son llevadas a cabo por diez de los 12 grupos considerados; $y$, con una frecuencia de nueve observatorios, la organización de eventos abiertos a la opinión pública, en los que el debate público y la presencia de medios suelen ser constantes.

Respecto a las alianzas que hacen los observatorios con otros miembros de la sociedad civil, no resulta menor que dos de los observatorios son, en sí mismos, una conjunción de organizaciones que se conformó con la finalidad explícita de incrementar su papel como actores en la arena pública y, por tanto, su incidencia en las políticas educativas (es el caso de Suma por la Educación y del CCAE). También se observa que realizan esta vinculación con más sociedad civil, incluso con instituciones con funciones y características diferentes de las suyas, como son las universidades, las fundaciones, la iniciativa privada y los medios de comunicación.

En cuanto a la alta frecuencia con la que los observatorios realizan acciones de análisis, investigación e indagación, así como de construcción y emisión de recomendaciones, se considera que ello da cuenta del valor que otorgan a la investigación educativa -entre otros medios de producción de evidencia-. Al ser esto de especial interés para el presente artículo, cabe recordar que los observatorios analizados están conformados, en una parte importante de los casos, por especialistas, ya sea por preparación académica o por el trabajo directo en el campo de su interés.

En el mismo sentido, es apreciable que la vinculación entre esta evidencia (emanada de la investigación y la evaluación) y las políticas públicas es una preocupación presente entre los observatorios ciudadanos de las políticas educativas en México, siendo en ella, posiblemente, donde mejor se aprecia el rol que depositan estas organizaciones en la investigación para la consecución de sus fines últimos. 
Tales preocupaciones pueden observarse en las citas de las siguientes líneas recuperadas de cuatro de los observatorios estudiados o de sus integrantes.

El OCE, según Latapí (2005, p. 8):

[Buscaría] ser una instancia de vigilancia social de las políticas educativas que ejerciera un seguimiento crítico sobre su formulación y ejecución y dialogara con las autoridades aportando conocimientos, juicios documentados y cuestionamientos [énfasis agregado]... se proponía también: abrir un espacio social para el análisis y discusión de las políticas seguidas, sensibilizar a la sociedad... y dar cauce a las demandas educativas de los sectores que no reciben la atención que merecen.

El Observatorio Veracruzano de la Educación (2011, p. 5) escribió lo siguiente en un documento entregado a las autoridades de la entidad federativa que le dio marco:

Para el OVE es fundamental que la sociedad civil y los gobernantes dimensionen la importancia de diseñar e implementar politicas educativas públicas transparentes, informadas y susceptibles de escrutinio pormenorizado [énfasis agregado]. La evaluación, la rendición de cuentas, la transparencia y el combate a la corrupción deben ser estándares de actuación permanente imprescindibles a lo largo y ancho del Sistema Educativo Veracruzano.

El CIEP (2019) se presenta en su página web de la siguiente forma: "Nuestra misión es democratizar las finanzas públicas y reducir la brecha de conocimiento [énfasis agregado] entre el gobierno y los distintos actores de la sociedad."

México Evalúa (2019), por otro lado, en su portal electrónico habla de esta manera sobre su fin último y su forma de trabajo: "Apoyamos los procesos de mejora de las políticas públicas a nivel federal, estatal y local mediante la generación y/o revisión de evidencia y la formulación de recomendaciones [énfasis agregado]."

Otro ejemplo de este interés, así como del esfuerzo de los observatorios por participar en la arena pública es la siguiente declaración 
del CEEY (2019) en su página de internet: "El espacio público es el principal [énfasis agregado] sobre el cual gira la misión del CEEY. Por eso, dedicamos un esfuerzo sistemático para observar, participar y opinar sobre temas y eventos puntuales". No queda duda de este esfuerzo cuando ocho de los 12 observatorios abordados participan en debates o entrevistas por radio o televisión, o buscan espacios en la prensa escrita. Sin embargo, existe una fuerte disparidad entre los observatorios focalizados y los no focalizados en esta actividad, pues mientras todos los segundos participan en estos medios de comunicación masiva (cuatro de cuatro observatorios), sólo la mitad de los primeros lo hacen (cuatro de ocho), aunque seis de ocho focalizados sí inician o participan en campañas, ninguno de los no focalizados lo hace. Se considera que esta radiografía inicial de fortalezas y posibles áreas de oportunidad de los observatorios de políticas educativas en México puede contribuir a identificar su potencial para incidir en la hechura de las políticas, a partir, quizá, de generar alianzas que les permitan aprender y apoyarse entre sí.

Se aprecia, pues, en general, que las acciones llevadas a cabo por estas figuras asociativas les permiten incrementar su capacidad técnica, tener una presencia reconocida en la arena pública, y aumentar su base y legitimidad sociales. De esto se sigue que todas las acciones realizadas por los observatorios de políticas educativas en México pueden incrementar su potencial para incidir de forma general en las políticas públicas y, de manera particular, para tender puentes entre éstas y la investigación educativa. Estas acciones suelen estar acompańadas, además, de diversos tipos de información que los observatorios hacen públicos (véase gráfica 4).

En la gráfica 4, que ordena de forma descendente los productos informativos producidos por los observatorios estudiados (según su frecuencia general), puede verse que las recomendaciones o directrices son el producto de información más común entre ellos, pues sólo uno no las genera. También con una alta frecuencia (diez de 12 observatorios) hacen públicos sus informes o reportes (ya sea de las actividades de la organización o del proceso indagatorio que realicen), los boletines o comunicados con su posición respecto a los temas de su interés, y contenido multimedia. Los observatorios también producen, aunque en una medida notablemente menor, 
artículos de opinión, indicadores técnicos, repositorios (o ligas con recomendaciones de lectura), newsletters con noticias de las propias organizaciones o para reportar los últimos acontecimientos en sus áreas de interés, documentos de trabajo, y hasta metodologías, rankings, herramientas web y glosarios (siendo los últimos cuatro los menos generados por los observatorios con una frecuencia de entre una y tres agrupaciones).

Es de resaltarse que en cada uno de los tipos de información existe una vasta variedad de productos entre los observatorios, los que permiten pensar en su múltiple potencial de incidencia. Un ejemplo de ello es el contenido multimedia, pues van desde infografías y videos, hasta plataformas interactivas y exposiciones fotográficas.

Gráfica 4. Tipo de información pública producida por los observatorios de políticas educativas en México, por su focalización

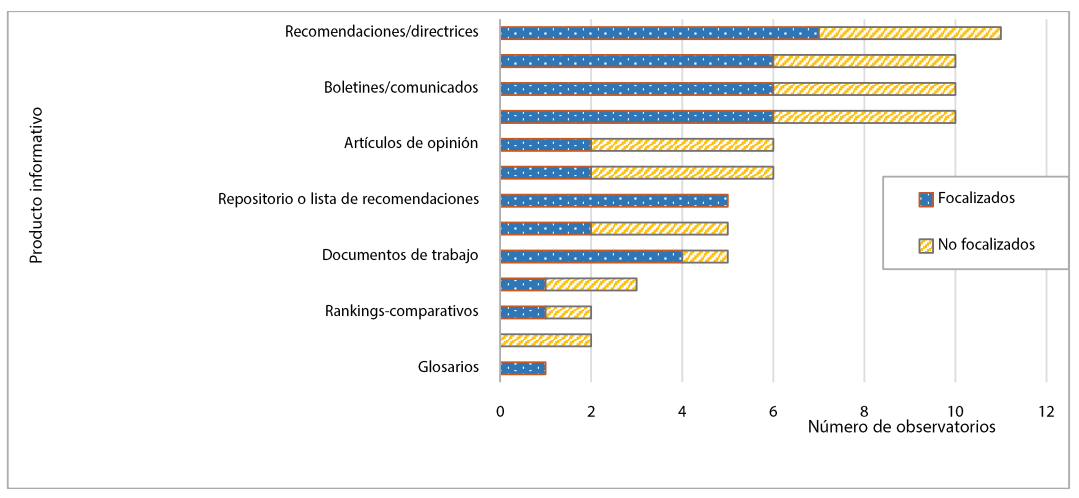

Nota. La frecuencia de observatorios registrados en cada producto de información corresponde netamente a cuántos de ellos han hecho público al menos un documento del tipo en cuestión. Algunos productos fueron contabilizados como parte de más de una categoría de producto. En el caso de los observatorios no focalizados sólo se consideraron los productos elaborados para la educación o que la incluyan. Se realizaron múltiples ajustes tanto en la cuantificación, como en los tipos de productos informativos sistematizados, en relación con lo colocado en una etapa previa en la ponencia base.

Fuente: tomado de Martínez Bordón, Reyes y Hermida, 2019, p. 20. Los datos son complementados y actualizados con información de las páginas web oficiales, redes sociales y producciones diversas de los observatorios analizados. Elaboración propia.

Se considera que la misma generación de estos productos de información es una muestra del interés de los observatorios por la investigación e indagación, así como del anhelo de que las autoridades tomen mejores decisiones de política educativa y que, de diferentes maneras, la ciudadanía resulte con los mayores beneficios posibles. 
Un ejemplo claro es la descripción que hace el IMCO (2019) de la herramienta web denominada "Mapa de reconstrucción escolar" que ha desarrollado desde marzo de 2018, junto con otras organizaciones de la sociedad civil e iniciativa privada, para monitorear, transparentar y acelerar la reconstrucción de las escuelas que fueron afectadas por los sismos de septiembre de 2017 en todo el país: "Buscamos que la herramienta ayude a organizaciones y autoridades a eficientar el uso de recursos [énfasis agregado] y, a la par, sirva a las comunidades educativas para corroborar, exigir y contribuir a la reconstrucción de sus planteles" [énfasis agregado].

\section{¿A quiénes dirigen su observación?: públicos objetivo}

Tal como se muestra en el cuadro 1, todos los observatorios estudiados señalan a la ciudadanía en general como su público objetivo, a la que siguen (en orden descendente) los hacedores de política, haciendo aquí la distinción de que, mientras dos de los ocho observatorios focalizados no buscan interpelarlos directamente, la totalidad de los no focalizados sí los consideran como público objetivo y aquellos dos parecen dirigirse a los segundos como público indirecto.

Pese a ello, el interés de ser escuchados por las autoridades no garantiza que, en efecto, lo sean. Los retos mencionados en el primer apartado de este artículo se les han presentado, en mayor o menor medida, y en diferentes momentos, a los observatorios ciudadanos de políticas educativas en México. Por ejemplo, ACUDE A. C. comparte cómo fue su relación con autoridades locales en la sistematización que Linares y Vélez (2007, p. 248), dos de sus miembros, hicieron sobre una de sus intervenciones:

Las alianzas y las articulaciones fueron posibles, por lo general, gracias a las relaciones con colegas que ocupan puestos en el gobierno, en las universidades y otras instancias. En el caso de las instancias gubernamentales, la relación dura sólo el tiempo que permanece el funcionario en su puesto y, en el mejor de los casos, hay que reconstruirla periódicamente.

Retomando el análisis de tendencias, la frecuencia general de los observatorios que señalan a otros públicos objetivos disminuye a la mitad (el caso de las organizaciones de la sociedad civil, OSC), y con- 
tinúa decreciendo. Si bien ello no es necesariamente negativo, puede ser una luz amarilla para el logro de incidencia en la agenda pública y de gobierno el que únicamente cuatro de los 12 observatorios dirijan sus productos a docentes y a madres y padres de familia. En el caso de los familiares, tres de los observatorios que apelan a ellos son focalizados y sólo uno no focalizado; mientras que quienes dirigen explícitamente sus productos a docentes son todos focalizados. Resulta preocupante que sólo tres de los 12 observatorios ciudadanos interpelen a los directivos de las comunidades escolares y a los estudiantes, siendo los tres de tipo focalizado.

Aunque la menor frecuencia entre los públicos objetivos directos sea presentada aquí en los académicos (pues sólo uno de cada tipo de observatorio los tiene como tales, dos en total), se considera que es un dato que tendrá que tomarse con cautela en espera de lo que entrevistas posteriores con los miembros de los observatorios puedan revelar. Lo anterior en cuanto muchas de las producciones de estas agrupaciones -sobre todo de las derivadas de investigación y análisis- poseen un lenguaje medianamente técnico y, además, son generados por miembros de los observatorios que son -o han sido-, en sí mismos, especialistas o académicos de alguna institución.

Cuadro 1. Públicos objetivo (directos) de los observatorios de políticas educativas en México

\begin{tabular}{|l|c|c|c|}
\hline \multirow{2}{*}{ Público objetivo } & \multicolumn{3}{|c|}{ Observatorios (frecuencia) } \\
\cline { 2 - 4 } & Focalizados & No focalizados & Total \\
\hline Ciudadanía en general & 8 & 4 & 12 \\
\hline Hacedores de política & 6 & 4 & 10 \\
\hline OSC & 5 & 1 & 6 \\
\hline (Ex) órganos autónomos & 4 & 1 & 5 \\
\hline Madres y padres & 3 & 1 & 4 \\
\hline Docentes & 4 & 0 & 4 \\
\hline Directivos & 3 & 0 & 3 \\
\hline Estudiantes & 3 & 0 & 3 \\
\hline Académicos & 1 & 1 & 2 \\
\hline
\end{tabular}

Fuente: elaboración propia a partir de las páginas web oficiales, redes sociales y producciones diversas de los observatorios abordados. Nota. Ninguno de los observatorios analizados posee un único público objetivo, por lo que no suman 12 a lo largo del listado de públicos. Cabe mencionar que una versión inicial de este ejercicio se encuentra en la ponencia a la que se ha hecho alusión. 
Resulta interesante también que los públicos objetivo de los observatorios tampoco son completamente estáticos, lo que habla del dinamismo de estas figuras, pues ha habido momentos en los que han enfocado más o menos sus esfuerzos hacia algunos de ellos. La radiografía aquí presentada muestra todos los públicos que han tenido los observatorios analizados a lo largo de su historia, lo cual no significa que no puedan cambiar, ni que su apelación a ellos posea la misma intensidad.

Un ejemplo de este cambio se verá próximamente ya que, antes de la desaparición del INEE, cinco de los 12 observatorios lo interpelaban, siendo únicamente uno de ellos de tipo no focalizado. Pese a que se encuentra pendiente conocer el impacto finalmente obtenido de apelar al instituto, no resultaba menor que existiera la posibilidad clara de que la rendición de cuentas diagonal que representa el monitoreo permanente de la ciudadanía organizada en los observatorios pudiera activar mecanismos de rendición de cuentas horizontales, como era el caso del INEE en cuanto era un órgano constitucionalmente autónomo, pues aun sin la posibilidad de sancionar legalmente a autoridades, poseía otros elementos normativos que, al menos, reconocían su función como contrapeso institucionalizado en la educación.

\section{PROPUESTA-MODELO PARA ANALIZAR Y POTENCIAR EL ROL VINCULANTE DE LOS OBSERVATORIOS DE POLÍTICAS EDUCATIVAS EN MÉXICO}

Conocer los públicos a los que se dirigen los observatorios de políticas educativas en México, así como las acciones y los productos de información por medio de los cuales lo hacen hace tangible el interés y el potencial de estas figuras de la sociedad civil para desempeñar un rol en la arena pública que los haga partícipes activos de la gobernanza del sistema educativo, de acuerdo con lo que se ha discutido a lo largo de este artículo.

De esta manera, después de la revisión de la literatura especializada y de los casos de observatorios ciudadanos de políticas educativas mexicanos, se hace la siguiente propuesta para analizar -e impulsarsu potencial de vincular la investigación educativa con las políticas 
públicas (véase gráfica 5). En este artículo, aunque se hacen ajustes importantes al esquema, se mantiene la idea original planteada en la ponencia a la que se ha hecho alusión (Martínez Bordón, Reyes y Hermida, 2019). El esquema se originó a partir de la revisión, tanto de las experiencias de observatorios de políticas educativas en México, como de literatura especializada (Ackerman, 2005; Fox y Aceron, 2016; Kingdon, 1995; Martínez Bordón, 2018; Martínez, Valencia y Díaz, 2014; Moreles, 2009; Natal y Díaz, 2014; OEA, 2015; Slavin, 2008a y 2008b).

La precisión inicial es que las líneas punteadas en el esquema propuesto representan los procesos de construcción de vínculos entre los tres elementos centrales: investigación y evaluación, observatorios ciudadanos y políticas educativas. De tal forma que, en la gráfica 5, puede visualizarse la posible dinámica por la cual se generan tres tipos de vínculos.

El primer vínculo es uno de fortalecimiento mutuo entre los observatorios ciudadanos y la evaluación e investigación educativas. Por un lado, los observatorios pueden: i) realizar investigaciones y evaluaciones para generar evidencia -altamente valorada por ellosrespecto a los ámbitos educativos a los que dan seguimiento; ii) retomar los hallazgos de evaluaciones e investigaciones emprendidas por otros actores; iii) sintetizar los resultados de éstas después de haberlas analizado; iv) traducir no sólo el lenguaje técnico utilizado en evaluaciones e investigaciones, sino los datos aislados, en general, para transformarlos en argumentos que incrementen su potencial de uso por tomadores de decisiones según lo reportado en diferentes estudios (Majone, 1997; Weiss, 2016); o, v) proponer temas de interés público para ser incorporados a las agendas de investigación y evaluación de otras instancias. Por el otro lado, la investigación y la evaluación pueden beneficiarse de la interpelación que les hacen los observatorios ciudadanos toda vez que, además de proponer o señalar a los especialistas aquellas temáticas que resultan socialmente relevantes, incrementan sus posibilidades de que la investigación y la evaluación sean incorporadas al proceso de las políticas educativas, pues, como plantea Latapí (2008, p. 295), "lo que descubrimos en nuestras investigaciones merece ser eficaz; abrámosle camino hacia la puesta en marcha”. 

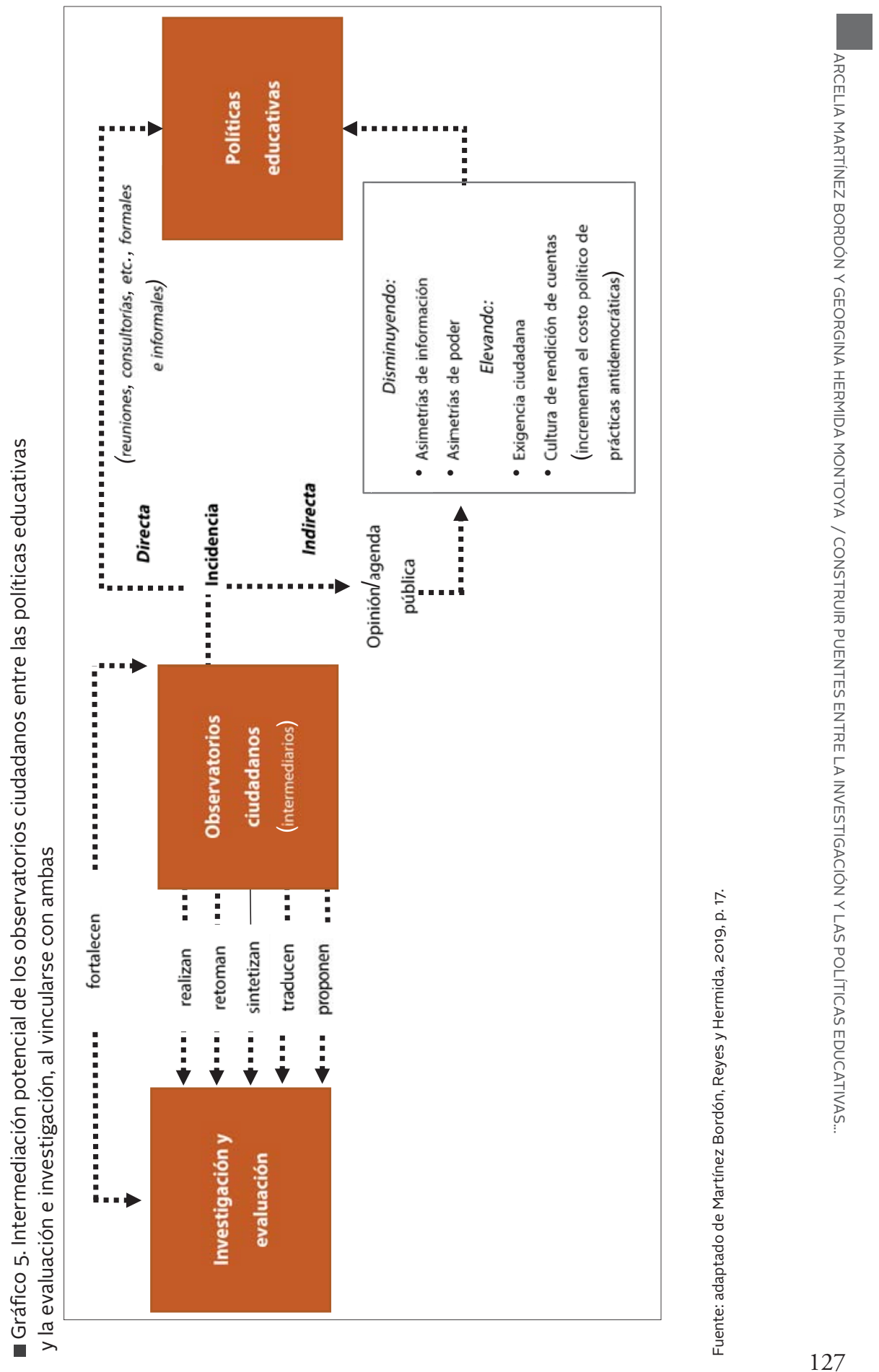
El segundo vínculo potencial supone la incidencia de los observatorios ciudadanos en el proceso de las políticas educativas, pudiendo ser de dos tipos: incidencia directa o indirecta. La primera ocurre cuando los observatorios han logrado posicionarse como actores con un lugar privilegiado en la arena pública o han construido relaciones con funcionarios públicos, lo que les permite participar directamente en la formulación y monitoreo de las políticas educativas, a través de reuniones, consultorías, entre otras, que pueden ser de tipo formal (con canales institucionales para ello) o informales. La incidencia indirecta, por su parte, acontece por medio de la influencia -en diferentes grados y formas- de los observatorios ciudadanos en el debate, la opinión y la agenda públicas, es decir, de lo considerado materia de interés público por la sociedad civil en general. En esa medida, los observatorios aludidos contribuyen a disminuir las asimetrías de información y poder entre la sociedad civil y sus gobernantes, además de elevar la exigencia ciudadana y la cultura de rendición de cuentas en la sociedad, lo que incrementa el costo político de que las autoridades lleven a cabo decisiones y prácticas antidemocráticas. Cabe señalarse que la incidencia directa e indirecta no son mutuamente excluyentes -ni teórica, ni empíricamente-, sino al contrario: entre más se fortalezca uno de los tipos de incidencia de los observatorios, les permite tener más presencia en la otra.

El tercer vínculo -y que ha sido el motivo para este artículo- son los puentes potenciales que pueden tenderse entre evaluación e investigación y políticas educativas, a través de la intermediación de los observatorios ciudadanos al interesarse éstos en generar o recuperar evidencia para dar seguimiento a las decisiones, acciones y omisiones de los tomadores de decisiones de política educativa, y al preocuparse por que los tomadores de decisiones retomen en el ejercicio de sus funciones las observaciones informadas que aquéllos les extienden directa o indirectamente. En última instancia, el impulso de políticas basadas en evidencia por parte de los observatorios ciudadanos puede contribuir a que éstos logren sus propósitos últimos y vean realizadas las transformaciones sociales anheladas pues, como sostienen Navarro, Zuñiga y Arenas (2018, p. 123): 
Justamente uno de los propósitos principales de diseñar políticas basadas en evidencia es hacerlas resistentes y blindarlas a presiones políticas y a grupos de intereses externos que no estén alineados con los objetivos de política nacionales. ... Es por esto que las EBP [políticas basadas en evidencia, por sus siglas en inglés] cumplen un rol fundamental en el fortalecimiento de la democracia y sus pilares (como por ejemplo, la rendición de cuentas).

Así, los tres vínculos analizados permiten pensar en los observatorios de políticas educativas como mecanismos de rendición de cuentas diagonal para mejorar la gobernanza del sistema educativo y, con ello, sus procesos y resultados.

\section{REFLEXIONES FINALES}

La intención de este artículo no es romantizar los observatorios ciudadanos, ni plantear la participación de la sociedad civil como panacea de las problemáticas del sistema educativo. Se reconoce que los alcances de los observatorios deben pensarse no sólo desde su potencial (aquí trabajado), sino también tomando en consideración los grandes retos a los que se enfrentan, desde cuestiones internas de definición, subsistencia y adaptación a los veloces cambios sociales y tecnológicos, hasta la existencia de marcos normativos precarios en términos de participación social, transparencia y racionalidad en la toma de decisiones. En especial, en cuanto estas agrupaciones operan en escenarios en los que, en palabras de Latapí (2005, p. 24), "no basta que los argumentos que aduzca [el] OCE [-o cualquier observatorio ciudadano-] respecto a una política (por adoptarse o ya aplicada) sean racionales y convincentes; tienen además que estar contextuados en las luchas de interés que rodean a esa política”. A ello se suma la falta de madurez de la cultura democrática entre la sociedad civil que mencionaba Latapí en 2005 y es aún visible hoy día.

Los balances sobre qué tanto los observatorios han logrado participar del ciclo de las políticas educativas, sin duda, tendrán que hacerse en momentos posteriores y con otras aproximaciones metodológicas. Sin embargo, recuperar las recomendaciones que hizo Don Pablo Latapí a la investigación en 2007 y a la luz de la X edición de 
la cátedra realizada en su honor, ha traído a estas páginas reflexiones sobre las posibilidades de los observatorios ciudadanos, en particular de los mexicanos, para tender puentes - hasta la fecha endebles, pero anhelados- entre la investigación educativa y las políticas públicas.

Los hallazgos que aquí se presentan permiten apreciar que el monitoreo ciudadano de las políticas educativas que realizan estas figuras asociativas, tanto ex post, como ex ante, es una actividad sumamente amplia, en cuanto a temáticas, acciones realizadas, tipos de información producida y públicos objetivo. Se sostiene, por tanto, que es precisamente esa riqueza la que puede superar las limitantes que ha experimentado la investigación para incidir en las políticas públicas, pues los observatorios ciudadanos pueden fungir como intermediarios que, al mantener lazos de mutuo fortalecimiento con ambos elementos, promueve el surgimiento de un tercer vínculo entre éstos. Por ello, se considera que los investigadores no deben hacer caso omiso de esta invitación pues, como señala Latapí (2008), la investigación requiere de canales distintos de los tradicionales de la academia para lograr su fin social último. Además, de acuerdo con este autor (2005), la sociedad civil organizada, con especial mención a los observatorios, juega un rol fundamental para contribuir en la maduración de la cultura democrática y, en esa medida, para hacer realidad los ideales de democracia.

Con este artículo se busca, pues, abonar a la discusión de, al menos, tres áreas interrelacionadas de la investigación educativa que pueden tener importantes repercusiones sociales. En primer lugar, se aborda el pendiente que representa la mayor vinculación entre la investigación y las políticas educativas, pero incorporando en el análisis a un actor que puede resultar clave para consolidar los puentes entre ambos campos. En segundo lugar, como sostenía Latapí al escribir sobre el OCE, cuando aquí se habla de observatorios ciudadanos que dan seguimiento a las políticas educativas, se trata de un tema de participación social en la educación. Ambas cuestiones llevan al tercer campo sobre el cual se reflexiona en este artículo: las posibilidades de mejorar la gobernanza del sistema educativo, en especial en un escenario como el mexicano, que parece no haber consolidado su democracia y, en algunos ámbitos, parece incluso retroceder. 
Estudiar las figuras ciudadanas que buscan impulsar mejoras en la vida pública del país desde la vigilancia activa, crítica y propositiva, cobra especial relevancia cuando las mejoras anheladas son en lo referente a un derecho humano que, como sostuviera Latapí (2009), difícilmente es exigible y justiciable, pese a encontrarse estipulado en las normas de mayor jerarquía a nivel nacional e internacional. Sin dejar de mencionar que el escenario político actual de México demanda una ciudadanía mucho más activa, ya que el único organismo público educativo con autonomía constitucional y especialidad técnica en educación, el INEE -también impulsado, en su momento, por un grupo de investigadores del que formaba parte Latapí- fue desaparecido con la reforma educativa del sexenio actual.

Con esta decisión política, se han mermado las condiciones para la rendición de cuentas en materia educativa por parte de las autoridades. A esto se suman los altos niveles de precariedad en la cultura democrática de quienes habitan México, acerca de lo que hay evidencia (Latapí, 2005; INEE, 2018a y 2018b), aun cuando distintos estudios (Latapí, 2005; Natal y Díaz, 2014) muestran que la sociedad civil se ha organizado cada vez en mayor medida. Así, parece existir una escasez de contrapesos que, sencillamente, luce lejos de combatirse sin la emergencia y el fortalecimiento de estrategias ciudadanas -como los observatorios- para exigir mejores políticas públicas que permitan el goce efectivo del derecho a una educación de calidad con equidad.

\section{REFERENCIAS BIBLIOGRÁFICAS}

Ackerman, J. (2005). Social Accountability in the Public Sector. A Conceptual Discussion. Social Development Papers. Participation and Civil Engagement. Paper No. 86. Washington: Banco Mundial.

Aguilar, L. (2006). Gobernanza y gestión pública. Ciudad de México: Fondo de Cultura Económica.

Bracho, T. (2016). Usos efectivos para la mejora: ¿Cómo hacemos para que esto ocurra? Gaceta de la Política Nacional de Evaluación Educativa en México, 2(4), 38-41.

Centro de Estudios Espinosa Yglesias (CEEY). (2019). Qué hacemos. Página web oficial del CEEY. Recuperado de https://ceey.org.mx/contenido/que-hacemos/ 
Centro de Investigación Económica y Presupuestaria (CIEP). (2019). Comunidad CIEP. Página web oficial del CIEP. Recuperado de https:// comunidad.ciep.mx/

Consejo Mexicano de Investigación Educativa (Comie) (coord.). (1995). Colección: Estados del conocimiento 2002-2011. Ciudad de México: Comie, ANUIES.

Consejo Mexicano de Investigación Educativa (Comie). (2003). Colección: La investigación educativa en México, 1992-2002. Ciudad de México: Comie, ANUIES.

Consejo Mexicano de Investigación Educativa (Comie). (2013). Colección: Estados del conocimiento 2002-2011. Ciudad de México: Comie.

Detrich, R., Keyworth, R., y States, J. (2016). Leveraging Evidence-based Practices: From Policy to Action. Learning Disabilities: A Contemporary Journal, 14(2), 121-142.

Dorantes-Salgado, D., Morale.-Osorio, G., y Torres-Waksman, A. (2019). Uso de la evaluación entre las organizaciones de la sociedad civil y su capacidad para transformar la politica pública. Congreso de Investigación sobre el Tercer Sector. La relevancia y los aportes de la sociedad civil en México, Guadalajara, Jalisco, México. Recuperado de https://www. cemefi.org/congresodeinvestigacion/memoria/Memoria_2019.pdf

Fierro, C. (2019). Ponencia presentada en la X Cátedra Pablo Latapi Sarre. Sistema Universitario Jesuita, Ciudad de México, México. [Archivo de video]. Recuperado de https://www.youtube.com/ watch? $\mathrm{v}=5 \mathrm{NsWNCo}$ dlQ \& $\mathrm{t}=0930 \mathrm{~s}$

Flores Crespo, P. (2013). El enfoque de la política basado en la evidencia. Análisis de su utilidad para la educación de México. Revista Mexicana de Investigación Educativa, 18(56), 265-290.

Fox, J., y Aceron, J. (2016). Doing Accountability Differently. A Proposal for the Vertical Integration of Civil Society Monitoring and Advocacy. Washington, D.C.: Accountability Research Center, Ateneo, School of Government, Anti-Corruption Research Center.

Hamui-Sutton, M. (2009). Observatorio Ciudadano de la Educación. Revista Mexicana de Investigación Educativa, 14(41), 619-636.

Instituto Mexicano para la Competitividad (IMCO). (2019). Mapa de reconstrucción escolar. Recuperado de http://reconstruccion.mejoratuescuela.org/ Instituto Nacional para la Evaluación de la Educación (INEE). (2018a). Estudio Internacional de Educación Cívica y Ciudadana (Cívica). En Evaluaciones al sistema educativo nacional, 2013-2018 (pp. 18-19). Ciudad de México: INEE. 
Instituto Nacional para la Evaluación de la Educación (INEE). (2018b). Civica. Una evaluación sobre la formación ciudadana. 9. Resultados 2016 (segunda parte). Ciudad de México: INEE. Recuperado de https://www.inee.edu.mx/wp-content/uploads/2018/12/P2A345.pdf Juárez, D. (2019). Ponencia presentada en la X Cátedra Pablo Latapí Sarre. Sistema Universitario Jesuita, Ciudad de México. [Archivo de video]. Recuperado de https://www.youtube.com/watch?v= $5 \mathrm{Ns}$ WNCo9dlQ\& $\mathrm{t}=2245 \mathrm{~s}$

Kingdon, J. (1995). Agendas, alternatives and public policies. Nueva York: Prentice Hall.

Latapí, P. (1977). Reflexiones acerca del "éxito" de la investigación educativa. Revista del Centro de Estudios Educativos, VII(4), 59-68.

Latapí, P. (2005). La participación de la sociedad en la definición de políticas públicas de educación. El caso de Observatorio Ciudadano de Educación. Perfiles educativos, XXVII(107), 7-39.

Latapí, P. (2008). ¿Recuperar la esperanza? La investigación educativa entre pasado y futuro. Revista Mexicana de Investigación Educativa, 13(36), 283-297.

Latapí, P. (2009). El derecho a la educación. Su alcance, exigibilidad y relevancia para la política educativa. Revista Mexicana de Investigación Educativa, 14(40), 255-287.

Linares, M., y Vélez, H. (2007). Las niñas y los niños como agentes de cambio social. En Y. Corona y M. Linares, Participación infantil y juvenil en América Latina (pp. 217-255). Ciudad de México: UAM, Childwatch International Research Network, Universitat de Valencia. Loyo, A., y Solórzano, C. (2013). Entrevista con Carlos Muñoz Izquierdo. La influencia de los resultados de investigación en la toma de decisiones de política educativa. Revista Mexicana de Investigación Educativa, 18(58), 969-987.

Majone, G. (1997). Evidencia, argumentación y persuasión en la formulación de políticas. México: Fondo de Cultura Económica.

Martínez Bordón, A. (2018). La investigación educativa y su capacidad para "iluminar" la toma de decisiones: reflexiones a "cuatro voces". Revista Latinoamericana de Estudios Educativos, XLVIII(2), 265-290.

Martínez Bordón, A., Reyes, A., y Hermida, G. (2019). Observatorios de políticas educativas: mecanismos ciudadanos para potenciar el uso de las evaluaciones y la rendición de cuentas. Ponencia en el XV Congreso Nacional de Investigación Educativa del Comie, Acapulco, Guerrero, 
México. Recuperado de http://www.comie.org.mx/congreso/memoriaelectronica/v15/doc/3376.pdf

Martínez, G., Valencia, O., y Díaz, O. (2014). Bases y precisiones conceptuales para el estudio de los Observatorios Ciudadanos. En A. Natal y O. Díaz, Observatorios Ciudadanos Nuevas Formas de Participación de la Sociedad (pp. 53-76). Ciudad de México: UAM-Lerma e Iztapalapa, Editorial Gernika.

México Evalúa. (2019). Página web oficial de México Evalúa. Recuperado de https:/www.mexicoevalua.org/00_home-mexico-evalua/educacion/

Moreles, J. (2009). Uso de la investigación social y educativa. Recomendaciones para la agenda de investigación. Perfiles Educativos, XXXI(124), 93-106.

Natal, A., y Díaz, O. (2014). ¿Qué son y cómo funcionan los observatorios ciudadanos? En A. Natal y O. Díaz, Observatorios Ciudadanos Nuevas Formas de Participación de la Sociedad (pp. 21-50). Ciudad de México: UAM-Unidad Lerma y Unidad Iztapalapa, Editorial Gernika.

Navarro, A., Zuñiga, A., y Arenas, L. (2018). El uso de la evidencia en las políticas: el caso de las Evaluaciones de desempeño y ejecución presupuestal en el sector educación en el Perú. Politai: Revista de Ciencia Politica, 9(17), 119-146.

Observatorio Ciudadano de la Educación (OCE). (2004). Comunicado no. 119. Quinto aniversario. La Jornada. Recuperado de https:// www.jornada.com.mx/2004/03/13/044n1 soc.php?origen=soc-jus. php\&fly=

Observatorio Veracruzano de la Educación (OVE). (2011). Lineas de politica educativa para Veracruz. Una propuesta desde la sociedad civil. Veracruz: OVE.

Olvera, A. (coord.) (2003). Sociedad civil, esfera pública y democratización en América Latina. Ciudad de México: Universidad Veracruzana, FCE.

Organización de los Estados Americanos. (2015). Observatorios de Políticas Públicas en las Américas. Una Guía para su diseño e implementación en nuestras administraciones públicas. Washington: OEA.

Parsons, W. (2007). Análisis de las decisiones. En Políticas públicas. Una introducción a la teoría y la práctica del análisis de políticas públicas (pp. 273-476). Ciudad de México: FLACSO-México. 
Peruzzotti, E., y Smulovitz, C. (2002). Held to Account. Experiences of Social Accountability in Latin America. Journal of Human Development, 3(2), 209-230.

Rodríguez, R. (2018). Ponencia presentada en la IX Cátedra Pablo Latapi Sarre. Sistema Universitario Jesuita, Guadalajara, Jalisco. [Archivo de video]. Recuperado de https://www.youtube.com/ watch? $=6 \mathrm{w} 6 \mathrm{BideXX}-48 \mathrm{t}=2706 \mathrm{~s}$

Sañudo, L. (2013). Uso de la producción del conocimiento en México. En M. López, L. Sañudo y R. Maggi, Investigaciones sobre la investigación educativa, 2002-2011 (pp. 495-500). Ciudad de México: Comie.

Schmelkes, S. (2018). Ponencia presentada en la IX Cátedra Pablo Latapi Sarre. Sistema Universitario Jesuita, Guadalajara, Jalisco. [Archivo de video]. Recuperado de https://www.youtube.com/ watch? $\mathrm{v}=6 \mathrm{w} 6 \mathrm{BideXX}-4 \& \mathrm{t}=0325 \mathrm{~s}$

Slavin, R. (2008a). Evidence-based reform in education: what will it take. European Educational Research Journal, 7(1), 124-128.

Slavin, R. (2008b). What works? Issues in synthesizing educational program evaluation. Educational Researcher, 37(1), 5-14.

Smulovitz, C., y Peruzzotti, E. (2003). Societal and Horizontal Controls. Two Cases about a Fruitful Relationship. En S. Mainwaring y C. WeIna (comps.), Democratic Accountability in Latin America (pp. 309331). Oxford: Oxford University Press.

Tiana, A. (1997). Tratamiento y usos de la información en evaluación. Madrid: Organización de Estados Iberoamericanos para la Educación, la Ciencia y la Cultura (OEI).

Universidad Iberoamericana (UIA) (presentador). (2019a). Cátedra Pablo Latapi [Archivo de video]. Ciudad de México: Educación Futura. Recuperado de https://www.youtube.com/watch?v=xmfmkviWS7g

Universidad Iberoamericana (UIA). (2019b). Cátedra Pablo Latapi 2019 [Archivo de video]. Ciudad de México: Educación Futura. Recuperado de https://www.youtube.com/watch?v=5NsWNCo9dlQ\&t=4s

Universidad Iberoamericana (UIA). (2019c). Cátedra Palo (sic) Latapi Día 2 [Archivo de video]. Ciudad de México: Educación Futura. Recuperado de https://www.youtube.com/watch?v=B4j82EE52UY

Universidad Iberoamericana (UIA). (2019d). CPL 2 [Archivo de video]. Ciudad de México: Educación Futura. Recuperado de https://www. youtube.com/watch?v=95dO93164Ow 
Weiss, C. (1979). The many meanings of research utilization. Public Administration Review, 39(5), 426-431.

Weiss, C. (2016). La investigación de políticas. ¿Datos, ideas o argumentos? En CAF. Banco de Desarrollo de América Latina. La evaluación de politicas. Fundamentos conceptuales y analíticos (pp. 169-203). Serie: Estado, Gestión Pública y Desarrollo en América Latina. Buenos Aires: CAF. 